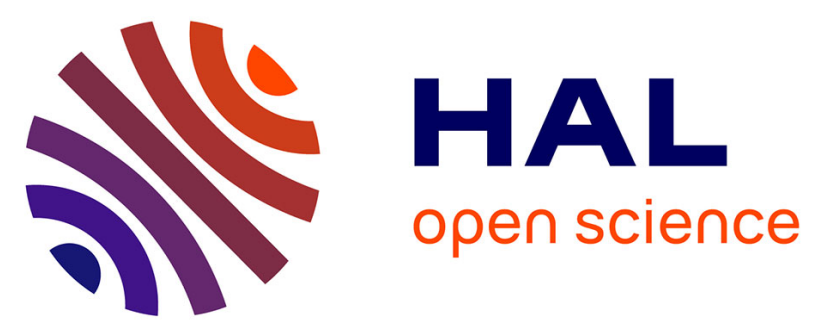

\title{
Summer to winter diurnal variabilities of temperature and water vapour in the lowermost troposphere as observed by HAMSTRAD over dome C, Antarctica
}

Philippe Ricaud, C. Genthon, P. Durand, Jean-Luc Attié, F. Carminati, G. Canut, J.-F. Vanacker, L. Moggio, Yann Courcoux, A. Pellegrini, et al.

\section{To cite this version:}

Philippe Ricaud, C. Genthon, P. Durand, Jean-Luc Attié, F. Carminati, et al.. Summer to winter diurnal variabilities of temperature and water vapour in the lowermost troposphere as observed by HAMSTRAD over dome C, Antarctica. Boundary-Layer Meteorology, 2012, 143 (1), pp.227-259. 10.1007/s10546-011-9673-6 . hal-00860358

\section{HAL Id: hal-00860358 https://hal.science/hal-00860358}

Submitted on 10 Sep 2021

HAL is a multi-disciplinary open access archive for the deposit and dissemination of scientific research documents, whether they are published or not. The documents may come from teaching and research institutions in France or abroad, or from public or private research centers.
L'archive ouverte pluridisciplinaire HAL, est destinée au dépôt et à la diffusion de documents scientifiques de niveau recherche, publiés ou non, émanant des établissements d'enseignement et de recherche français ou étrangers, des laboratoires publics ou privés. 


\title{
Summer to Winter Diurnal Variabilities of Temperature and Water Vapour in the Lowermost Troposphere as Observed by HAMSTRAD over Dome C, Antarctica
}

\author{
P. Ricaud • C. Genthon • P. Durand • J.-L. Attié • \\ F. Carminati - G. Canut - J.-F. Vanacker • \\ L. Moggio - Y. Courcoux - A. Pellegrini - T. Rose
}

\begin{abstract}
The HAMSTRAD $\left(\mathrm{H}_{2} \mathrm{O}\right.$ Antarctica Microwave Stratospheric and Tropospheric Radiometers) microwave radiometer operating at $60 \mathrm{GHz}$ (oxygen line, thus temperature) and $183 \mathrm{GHz}$ (water vapour line) has been permanently deployed at the Dome $\mathrm{C}$ station, Concordia, Antarctica $\left[75^{\circ} 06^{\prime} \mathrm{S}, 123^{\circ} 21^{\prime} \mathrm{E}, 3,233 \mathrm{~m}\right.$ above mean sea level] in January 2010 to study long-term trends in tropospheric absolute humidity and temperature. The great sensitivity of the instrument in the lowermost troposphere helped to characterize the diurnal cycle of temperature and $\mathrm{H}_{2} \mathrm{O}$ from the austral summer (January 2010) to the winter (June 2010) seasons from heights of 10 to $200 \mathrm{~m}$ in the planetary boundary layer (PBL). The study has characterized the vertical resolution of the HAMSTRAD measurements: $10-20 \mathrm{~m}$ for
\end{abstract}

P. Ricaud · P. Durand · J.-L. Attié · F. Carminati

Laboratoire d'Aerologie/CNRS, UMR 5560, Toulouse, France

C. Genthon

LGGE/CNRS, Grenoble, France

G. Canut

Leeds University, Leeds, UK

J.-F. Vanacker

IPEV, Brest, France

L. Moggio · A. Pellegrini

ENEA, Rome, Italy

Y. Courcoux

OPAR/UMS 3365/CNRS, St. Denis, La Réunion, France

T. Rose

Radiometer Physics GmbH, Meckenheim, Germany

Present Address:

P. Ricaud $(\varangle) \cdot$ J.-L. Attié · F. Carminati

Météo-France, GAME/CNRS, URA 1357, Toulouse, France

e-mail: philippe.ricaud@aero.obs-mip.fr 
temperature and 25-50 m for $\mathrm{H}_{2} \mathrm{O}$. A strong diurnal cycle in temperature and $\mathrm{H}_{2} \mathrm{O}$ (although noisier) has been measured in summertime at $10 \mathrm{~m}$, decreasing in amplitude with height, and phase-shifted by about $4 \mathrm{~h}$ above $50 \mathrm{~m}$ with a strong $\mathrm{H}_{2} \mathrm{O}$-temperature correlation $(>0.8)$ throughout the entire PBL. In autumn, whilst the diurnal cycle in temperature and $\mathrm{H}_{2} \mathrm{O}$ is less intense, a 12-h phase shift is observed above $30 \mathrm{~m}$. In wintertime, a weak diurnal signal measured between 10 to $200 \mathrm{~m}$ is attributed to the methodology employed, which consists of monthly averaged data, and that combines air masses from different origins (sampling effect) and not to the imprint of the null solar irradiation. In situ sensors scanning the entire 24-h period, radiosondes launched at 2000 local solar time (LST) and European Centre for Medium-Range Weather Forecasts (ECMWF) analyses at 0200, 0800, 1400 and 2000 LST agree very well with the HAMSTRAD diurnal cycles for temperature and relatively well for absolute humidity. For temperature, HAMSTRAD tends to be consistent with all the other datasets but shows a smoother vertical profile from 10 to $100 \mathrm{~m}$ compared to radiosondes and in-situ data, with ECMWF profiles even smoother than HAMSTRAD profiles, and particularly obvious when moving from summer to winter. For $\mathrm{H}_{2} \mathrm{O}$, HAMSTRAD measures a much moister atmosphere compared to all the other datasets with a much weaker diurnal cycle at $10 \mathrm{~m}$. Our study has helped characterize the time variation of the PBL at Dome C with a top around $200 \mathrm{~m}$ in summertime decreasing to $30 \mathrm{~m}$ in wintertime. In summer, from 2000 to 0600 LST a stable layer is observed, followed by a well-mixed layer the remaining time, while only a nocturnal stable layer remains in winter. In autumn, a daytime convective layer shallower than the nocturnal stable layer develops.

Keywords Absolute humidity - Antarctica - ECMWF analyses · Microwave radiometry · Planetary boundary layer . Temperature

\section{Introduction}

The Antarctic plateau (average altitude 2,500 m) is one of the coldest and driest places on Earth. For these reasons, numerous atmospheric studies have been made, and are nowadays taking place, focused on: the evolution of climate (e.g., Hines et al. 2004), processes within the planetary boundary layer (PBL) (e.g., Aristidi et al. 2005; Town and Walden 2009), reactive species interacting with the snowpack (e.g., Davis et al. 2001; Jones et al. 2001) and site-seeing investigations for astronomical purposes (e.g., Aristidi et al. 2003).

Depending upon the season and the location, complex processes mainly involving the interaction between the atmosphere and the ice sheet occur, the majority of them strongly dependent upon the intensity of the incoming shortwave solar radiation. At $75^{\circ} \mathrm{S}$ in summer, daylight lasts $24 \mathrm{~h}$ thus the cloud-free incoming shortwave radiation reaching the surface at sea level, although high $\left(650 \mathrm{~W} \mathrm{~m}^{-2}\right)$ at 1200 local solar time (LST), is not negligible $\left(100 \mathrm{~W} \mathrm{~m}^{-2}\right)$ at $0000 \mathrm{LST}$ (Fig. 1). According to King et al. (2006), incoming shortwave radiation at noon should be about $60 \mathrm{~W} \mathrm{~m}^{-2}$ greater at Dome $\mathrm{C}$ than at sea level. Since the surface albedo is close to unity or, at least, greater than 0.8 due to the presence of snow at the surface, the cloud-free outgoing shortwave radiation is also very high at $1200 \mathrm{LST}$ $\left(500 \mathrm{~W} \mathrm{~m}^{-2}\right)$ and, at $0000 \mathrm{LST}$, of the same order of magnitude but slightly less than the cloud-free incoming shortwave radiation. Consequently, a mixed layer develops in the morning, increasing in height until afternoon. Indeed, the mixed layer is observed to reach about $50 \mathrm{~m}$ above ground level at Halley Bay $\left(75^{\circ} \mathrm{S}, 26^{\circ} \mathrm{W}, 30 \mathrm{~m}\right.$ above mean sea level (a.m.s.l.)) on the Brunt ice shelf, and up to about $350 \mathrm{~m}$ above ground level at Dome $\mathrm{C}\left(75^{\circ} \mathrm{S}, 123^{\circ} \mathrm{E}\right.$, $3,233 \mathrm{~m}$ a.m.s.1.) $1,100 \mathrm{~km}$ from the coast (King et al. 2006) because of the positive radiative 


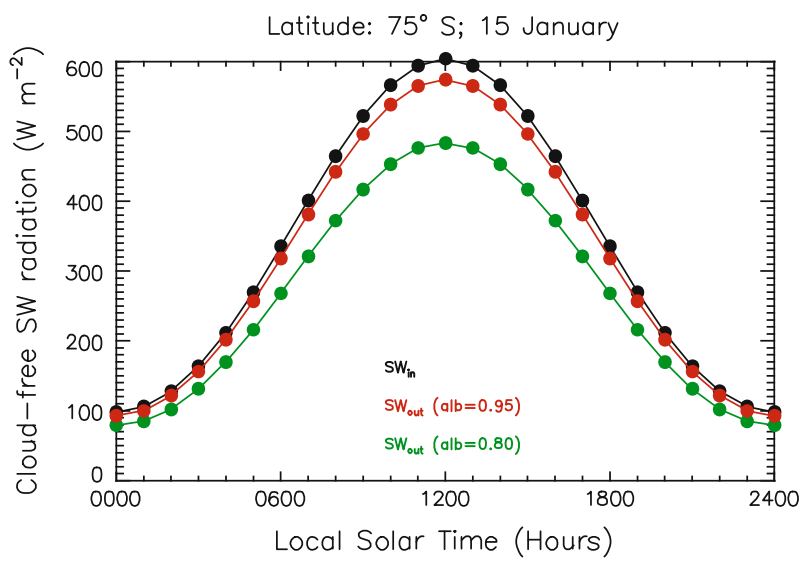

Fig. 1 Diurnal variation at $75^{\circ} \mathrm{S}$ on 15 January (LST) and at sea level for cloud-free conditions of: incoming shortwave radiation (black filled circles), outgoing shortwave radiation with a surface albedo of 0.95 (red filed circles) and a surface albedo of 0.80 (green filled circles) (Calculated from http://people.cas.sc.edu/carbone/ modules/mods4car/shortwave/index.html.)

balance reaching $40 \mathrm{~W} \mathrm{~m}^{-2}$ at Dome C (Aristidi et al. 2005) between 1200 and 1400 LST. In these particular conditions, a strong diurnal variation in temperature is observed near the surface that can be greater than $5 \mathrm{~K}$ in magnitude, and in surface albedo from 0.82 at local noon to 0.95 at local midnight (King et al. 2006) at Dome C. The near-surface studies are of particular interest since experiments have already shown strong temperature inversions around local midnight of about $3-7 \mathrm{~K}$ within a few tens of metres $(0.75-1.75 \mathrm{~K}$ per $10 \mathrm{~m})$ at Dome C (Genthon et al. 2010).

From mid-February at $75^{\circ} \mathrm{S}$, the incoming shortwave radiation is null at local midnight and has decreased to less than $500 \mathrm{~W} \mathrm{~m}^{-2}$ at $1200 \mathrm{LST}$ (Fig. 2). Then the mixed layer commences to have a sharp night-day transition and develops shallower compared to summertime. Moving to winter, when reaching the end of April to the beginning of May at $75^{\circ} \mathrm{S}$, daylight is brief $(<2 \mathrm{~h})$, and the cloud-free incoming and outgoing shortwave radiative fluxes become negligible. From this time of the year to the recovery of daylight in August, the PBL is much shallower and rather stable. Indeed, in winter conditions, the radiative balance is negative and the strongest temperature inversions are observed (Hudson and Brandt 2005) of $20 \mathrm{~K}$ over South Pole and $25 \mathrm{~K}$ on average over the highest part of the Antarctic Plateau. The presence of gravitational downslope flows is induced by these persistent strong inversion conditions producing katabatic winds (Connolley 1996). Furthermore, these conditions favour the presence of strong long-lived stable stratification of the air close to the surface.

The permanent Concordia (Dome C) station is jointly operated by the French Institut polaire français Paul-Emile Victor (IPEV) and the Italian Programma Nazionale Ricerche in Antartide (PNRA). Considering all the processes that play a key role in the evolution of temperature depending on the season, the Dome $\mathrm{C}$ station is extremely interesting for studying the diurnal variations of temperature and humidity from summertime to wintertime. Indeed, the site is situated on the Antarctic Plateau at 3,233 m a.m.s.1., with 24-h continuous daylight during summertime and darkness during wintertime (Fig. 2); climatological near-surface air temperature ranges between -40 and $-20^{\circ} \mathrm{C}$ in summertime (Tomasi et al. 2006), and between -80 and $-60^{\circ} \mathrm{C}$ in wintertime (Carminati et al. 2011a, manuscript in preparation). Being situated at the top of a large dome, there are negligible katabatic winds, compared with those encountered at the coastal Dumont d'Urville station $\left(66^{\circ} \mathrm{S}, 140^{\circ} \mathrm{E}\right.$, 


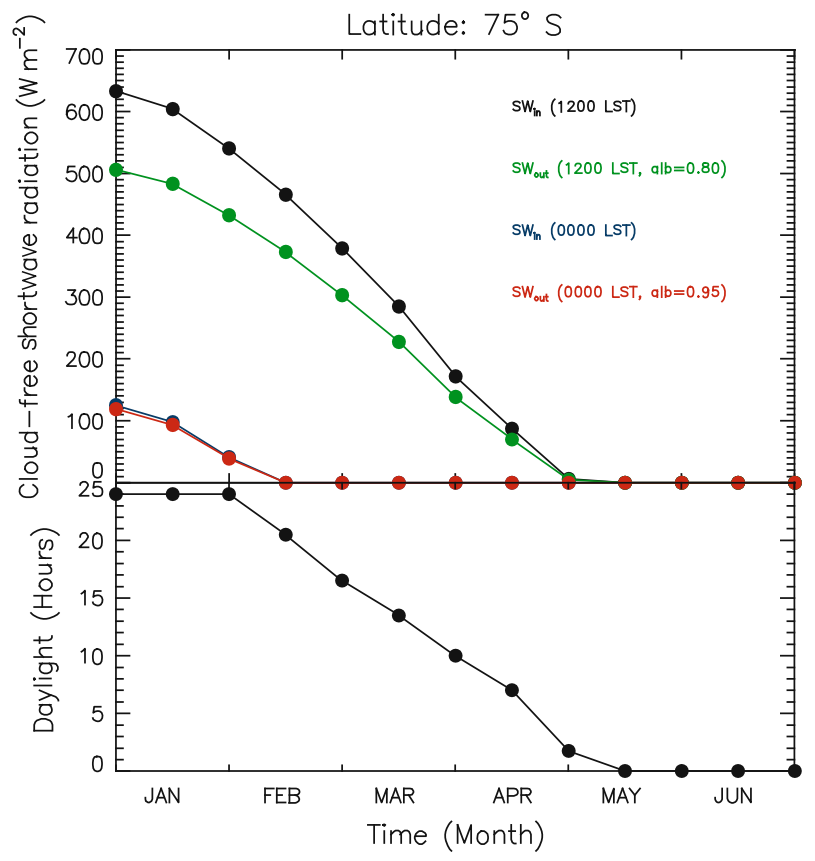

Fig. 2 Top Evolution from January to June for cloud-free conditions at $75^{\circ} \mathrm{S}$ and sea level of: incoming shortwave radiation at 1200 LST (black filled circles), and at 0000 LST (blue filled circles), outgoing shortwave radiation at 1200 LST with a surface albedo of 0.80 (green filled circles) and at 0000 LST with a surface albedo of 0.95 (red filled circles). Bottom daylight evolution at $75^{\circ} \mathrm{S}$ from January to June (Calculated from http://people.cas.sc.edu/carbone/modules/mods4car/shortwave/index.html.)

sea level), and wind speed very unlikely exceeds $5 \mathrm{~m} \mathrm{~s}^{-1}$ over the year although extreme winds up to $15 \mathrm{~m} \mathrm{~s}^{-1}$ have been already observed (King et al. 2006). Interestingly, whatever the season considered, when temperature decreases, the humidity precipitates in the form of light ice crystals. Clouds are also very unlikely over the station, and are mainly elevated cirrus clouds.

High altitude sites in Antarctica are particularly suited for millimetre and sub-millimetre atmospheric studies because of the extremely cold $\left(<-20^{\circ} \mathrm{C}\right)$ and dry (integrated water vapour less than $1 \mathrm{~mm}$ ) conditions encountered in the lower part of the troposphere all year long. The HAMSTRAD $\left(\mathrm{H}_{2} \mathrm{O}\right.$ Antarctica Microwave Stratospheric and Tropospheric Radiometers) programme aims at developing two ground-based microwave radiometers to sound tropospheric and stratospheric water vapour $\left(\mathrm{H}_{2} \mathrm{O}\right)$ above the Dome $\mathrm{C}$ (Concordia Station), Antarctica over a decadal time period. Up to now, only one microwave radiometer has been used for the measurement of tropospheric $\mathrm{H}_{2} \mathrm{O}$ (at $183 \mathrm{GHz}$ from the water vapour line) and temperature (at $60 \mathrm{GHz}$ from the detection of the oxygen line). The main objective of our project was to detect trends in $\mathrm{H}_{2} \mathrm{O}$ at high latitudes where processes affecting the $\mathrm{H}_{2} \mathrm{O}$ evolution are less complex than in the tropics (SPARC Assessment 2000). The first measurements of temperature and absolute humidity by HAMSTRAD at the Dome C station commenced on 22 January 2009 and lasted 12 days. The continuous and automated measurements started a year later, on 8 January 2010, and HAMSTRAD has been successfully in operation since then. Although the instrument was primarily dedicated to sound the free troposphere, we have shown (Ricaud et al. 2010c) that HAMSTRAD was also able to sound the lowermost troposphere to study processes in the PBL. We have taken the opportunity of a continuous 
long time series of HAMSTRAD measurements from January to June 2010 to study in detail the diurnal variabilities of temperature and $\mathrm{H}_{2} \mathrm{O}$ in the lowermost troposphere from summer to winter, to compare them against in situ sensors, radiosondes and the ECMWF analyses, and to infer the diurnal evolution of the different layers within the PBL depending on the considered seasons.

The aims of the paper are, (1) to present the diurnal variations of temperature and absolute humidity from summer to winter as observed by the HAMSTRAD microwave radiometer in the Antarctic PBL (from 10 to $200 \mathrm{~m}$ above the altitude of the site) at the Dome C station; (2) to assess their quality by comparing them with radiosonde data at only one fixed time period (namely, 2000 LST), in situ sensors scanning the 24-h local times from heights of 4 to $45 \mathrm{~m}$, and the analyses of the European Centre for Medium-Range Weather Forecasts (ECMWF) at four fixed local times (namely, 0200, 0800, 1400, 2000 LST); and (3) to highlight the processes producing these diurnal variations regarding the considered seasons. In that respect, we extend both in altitude and time the results presented in Genthon et al. (2010) based upon in situ and ECMWF analyses below $45 \mathrm{~m}$ in summertime.

The manuscript is structured as follows: Sect. 2 presents the different datasets used in our analysis, while Sect. 3 shows the diurnal variations of temperature and humidity as measured by HAMSTRAD depending on the month. The processes that produce these variations regarding time and altitude are also discussed in this section. Section 4 assesses the quality of the diurnal variations of temperature and absolute humidity as measured by HAMSTRAD by comparison with ECMWF analysis data, radiosonde measurements, and in situ sensors considering both the vertical profiles versus time and the time evolution versus height. Sect. 5 details the diurnal variations of the different layers present within the PBL according to the considered season. Finally, Sect. 6 concludes our study, while an Appendix provides details of a study to estimate the vertical resolution of the HAMSTRAD measurements of temperature and $\mathrm{H}_{2} \mathrm{O}$ below $200 \mathrm{~m}$.

\section{Datasets}

\subsection{HAMSTRAD}

The HAMSTRAD-Tropo (hereafter named HAMSTRAD) radiometer has already been presented in Ricaud et al. (2010a). To sum up, it is a state-of-the-art microwave radiometer dedicated to the measurement of tropospheric $\mathrm{H}_{2} \mathrm{O}$ at $169-197 \mathrm{GHz}$ (G-band, strong water vapour line at $183.3 \mathrm{GHz})$, together with tropospheric temperature from the oxygen $\left(\mathrm{O}_{2}\right)$ line (51-59 GHz, V-band, lower frequency wing of the $\mathrm{O}_{2}$ line), in a very cold and dry environment such as that encountered at Dome $\mathrm{C}$ all through the year. From these emission lines, absolute humidity and temperature vertical profiles can be retrieved from the surface to about $10 \mathrm{~km}$ above the surface with a temporal resolution of $7 \mathrm{~min}$, although, above the site, the instrument loses sensitivity at an altitude of about $6 \mathrm{~km}$.

The great majority of ground-based microwave radiometers dedicated to sounding tropospheric $\mathrm{H}_{2} \mathrm{O}$ uses the $6_{16}-5_{23}$ transition line at $22.235 \mathrm{GHz}$ (e.g., Westwater et al. 2004), which can be detected in the majority of sites around the world. Unfortunately, the weak intensity of the line is the major drawback for the detection of $\mathrm{H}_{2} \mathrm{O}$ in extremely cold and dry conditions such as those encountered at high latitudes, and particularly over the Antarctic plateau. The best candidate for detecting $\mathrm{H}_{2} \mathrm{O}$ in these extreme environments is the $313-$ $2_{20}$ transition line at $183.310 \mathrm{GHz}$ (e.g., Pazmany 2007; Cimini et al. 2007a). Radiometers operating at this frequency have been successfully deployed in the Arctic, e.g. in the Arctic 
Winter Experiment held at the Atmospheric Radiation Measurement (ARM) Program's North Slope of Alaska (NSA) site near Barrow (Alaska, USA) (Westwater et al. 2006) with the ground-based scanning radiometer (GSR) (Cimini et al. 2007b) measuring, among other transitions, the $183-\mathrm{GHz} \mathrm{H}_{2} \mathrm{O}$ line. In these dry Arctic conditions, precipitable water vapour, of the order of 1-2 mm, can be estimated to within 5\% uncertainty (Racette et al. 2005). We thus developed and installed an automated instrument to be operated continuously over several years in even more extreme conditions, for precipitable water vapour amounts much less than $1 \mathrm{~mm}$ and temperatures less than $-70^{\circ} \mathrm{C}$ (Tomasi et al. 2006).

HAMSTRAD was first deployed at the Pic du Midi station $\left(42^{\circ} 56^{\prime} \mathrm{N}, 0^{\circ} 08^{\prime} \mathrm{E}, 2,877 \mathrm{~m}\right.$ a.m.s.l., France) from February to June 2008 and a comprehensive assessment exercise regarding $\mathrm{H}_{2} \mathrm{O}$ measurements was performed against radiosondes and the spaceborne instrument Infrared Atmospheric Sounding Interferometer (IASI) onboard the MetOp-A platform, together with the output fields from a mesoscale meteorological model MESO-NH (Ricaud et al. 2010b). The HAMSTRAD radiometer was then deployed outdoors at Dome $\mathrm{C}$ in January-February 2009 and measurements have been validated against radiosondes, in situ sensors, and satellite measurements (Ricaud et al. 2011).

On 8 January 2010, the HAMSTRAD radiometer was deployed outdoors and run continuously until 16 January 2010 after which it was installed inside a fully equipped shelter and has been in an automated operation since. A comprehensive validation exercise is actually performed regarding the 2010 measurements and genuine scientific results have already been highlighted regarding short-term (diurnal variation) and mid-term (seasonal variation) variability of $\mathrm{H}_{2} \mathrm{O}$ and temperature in the PBL (Ricaud et al. 2010c).

Considering theoretical calculations (Ricaud et al. 2010a) and actual measurements performed at the Pic du Midi (Ricaud et al. 2010b) and Dome C (Ricaud et al. 2011), the derived accuracies of the HAMSTRAD individual measurements of temperature and $\mathrm{H}_{2} \mathrm{O}$ below $200 \mathrm{~m}$ in a boundary-layer measurement mode (namely measuring at very low elevation angles) are about $0.25-1.0 \mathrm{~K}$ and $0.01-0.03 \mathrm{~g} \mathrm{~m}^{-3}$, respectively. From theoretical calculations (Ricaud et al. 2010a), the vertical resolution of temperature and $\mathrm{H}_{2} \mathrm{O}$ vertical profiles is expected to be about $50 \mathrm{~m}$ and $100 \mathrm{~m}$, respectively. The vertical resolution of the HAMSTRAD measurements below $200 \mathrm{~m}$ has been revisited considering the January-June 2010 measurements to be $10-20 \mathrm{~m}$ for temperature and $25-50 \mathrm{~m}$ for $\mathrm{H}_{2} \mathrm{O}$ (see the Appendix).

The measurements of temperature and absolute humidity have been reduced to 241 -h bins and monthly-averaged over the period from January to June 2010, namely from summer to winter. Below $200 \mathrm{~m}$, the vertical profiles of the HAMSTRAD measurements are retrieved at $0,10,30,50,75,100,125,150$ and $200 \mathrm{~m}$, and when operating outdoors (indoors), the instrument was at an altitude of $\approx 1.5 \mathrm{~m}(\approx 3.0 \mathrm{~m})$. To cope with the ambiguity in the lowermost height of the HAMSTRAD profiles being either 1.5 or $3 \mathrm{~m}$ above the surface, we have interpolated the HAMSTRAD measurements onto a fixed grid at heights of $0,10,30,50,75,100,125$, 150 and $200 \mathrm{~m}$ whatever the period considered, with the instrument being indoors or outdoors. We intentionally neglected the surface level since it is rather misleading because it supposes measurements are performed at the surface, but no sensor used in our analysis (HAMSTRAD, in situ, radiosondes) had such a capability. Furthermore, the vertical resolution of the microwave instrument (10-50 $\mathrm{m}$ as presented in the Appendix), together with the measurement method at different elevations, degrade the sensitivity of the measurements at the Earth's surface. Consequently, for these reasons, we only show HAMSTRAD results at heights of $10,30,50,75,100,125,150$ and $200 \mathrm{~m}$ above the surface. Note that, in January 2010, due to a lack of data because of the setting up of the instrument and of its tuning, the analysis window has been seriously reduced. For the temperature study, we have averaged data from 8 to 31 January 2010 whilst, for the $\mathrm{H}_{2} \mathrm{O}$ study, we only used data from 16 to 22 January 2010 . 
For each month between January and June 2010, averaging HAMSTRAD measurements within 24 1-h bins results in 500-700 temperature profiles and $200-250 \mathrm{H}_{2} \mathrm{O}$ profiles, except in January 2010 when the number of $\mathrm{H}_{2} \mathrm{O}$ profiles is reduced to about 50 since only one week of measurements is used. If we now consider the HAMSTRAD measurements as noncorrelated with a Gaussian random noise, the estimated error in the hourly profile for each month ranges from 0.01 to $0.04 \mathrm{~K}$ for temperature and from 0.0007 to $0.002 \mathrm{~g} \mathrm{~m}^{-3}$ for $\mathrm{H}_{2} \mathrm{O}$, except in January 2010 when the hourly error is no better than $0.002-0.004 \mathrm{~g} \mathrm{~m}^{-3}$ due to the limited number of profiles used. By averaging such a great quantity of data, we intend to increase the signal-to-noise ratio (SNR) of the measurements within each 1-h bin. But the systematic error arising from different sources (calibration, spectroscopy, measurement technique at different elevations, retrieval method, etc.) is indeed unchanged. A means of estimating such a systematic error is to consider the biases between HAMSTRAD and all other datasets.

\subsection{ECMWF Analyses}

The ECMWF analyses assimilate observations made worldwide into a meteorological model. The nominal (Gaussian grid) horizontal resolution is approximately $50 \mathrm{~km}$, but primitive equation variables are continuously defined through spherical harmonics. In the vertical at Dome $\mathrm{C}$, there are six model levels within the lowest $200 \mathrm{~m}$ of the atmosphere, approximately at $8,30,55,90,130$ and $180 \mathrm{~m}$ above the surface, and one just above $(230 \mathrm{~m})$. The model surface elevation at Dome $\mathrm{C}$ is $3230 \mathrm{~m}$ a.m.s.l., only $3 \mathrm{~m}$ different from the observed surface altitude.

Although the ECMWF model is not tuned for Antarctic plateau conditions, Genthon et al. (2010) report that the performances of the ECMWF analyses are satisfactory under these extreme conditions. The approach used here is generally appropriate for evaluating the ability of the analyses to reproduce the timing and character of diurnal cycles in temperature and $\mathrm{H}_{2} \mathrm{O}$ with a great amount of available data. The analyses themselves are only available at a 6-h interval, which is sufficient to capture some characteristics of the diurnal cycle.

The ECMWF analyses of temperature and absolute humidity have been sorted out into four 1-h bins and monthly averaged over all the periods from January to June 2010, corresponding to outputs at 0000, 0600, 1200 and 1800 UTC, thus 0800, 1400, 2000 and 0200 LST, respectively. ECMWF vertical profiles of temperature and absolute humidity have been linearly interpolated onto the HAMSTRAD grid, namely at 10, 30, 50, 75, 100, 125, 150 and $200 \mathrm{~m}$ above the surface. Note that, in January 2010, to be consistent with the analysis window of the HAMSTRAD available measurements, ECMWF model temperature and $\mathrm{H}_{2} \mathrm{O}$ data were averaged from 8 to 31 January, and from 16 to 22 January, respectively.

\subsection{Radiosondes}

In 2010, we used data from Vaisala radiosondes type RS-92SPGW that measure air temperature, pressure, relative humidity and wind. One launch was conducted each day at 1200 UTC (2000 LST). These radiosondes make use of twin-heated humidity sensors that partially remove the dry bias detected in previous versions of radiosonde (Mattioli et al. 2008).

The first record in the edited radiosonde data file actually represents the measurement at the ground station. All other data (pressure, temperature and humidity) are actual measurements from the radiosonde. Therefore, depending on the ascent rate of the balloon, 
the first measurement of the radiosonde is typically from 4 to $6 \mathrm{~m}$ above ground. Thus, as for HAMSTRAD, we will not consider the measurements at the surface.

Temperature and humidity radiosonde measurements have been linearly interpolated onto the HAMSTRAD grid, namely at 10, 30, 50, 75, 100, 125, 150 and $200 \mathrm{~m}$ above the surface, and monthly averaged from January to June 2010. Note that, in January 2010, temperature and $\mathrm{H}_{2} \mathrm{O}$ radiosonde data were averaged from 8 to 31 January, and from 16 to 22 January, respectively.

\subsection{Tower-Based Sensors}

During the 2010 measurement period, in situ Humicap and force-ventilated PT100 sensors were installed along the 45-m high tower for measuring humidity and temperature, respectively. Basically, six levels of measurements were available at 3.5, 10.6, 18.0, 25.3, 32.7 and $41.9 \mathrm{~m}$, and the data were linearly interpolated (and extrapolated) onto the HAMSTRAD grid at 10,30 , and $50 \mathrm{~m}$ above the surface. Temperature and humidity in situ measurements were sorted into 24 1-h bins and monthly averaged from January to June 2010. As in the other datasets, note that, in January 2010, temperature and $\mathrm{H}_{2} \mathrm{O}$ in situ data were averaged from 8 to 31 January, and from 16 to 22 January, respectively.

Details of the instrumental set-up are available in Genthon et al. (2010) except that the temperature data used here are from PT100 DIN IEC 751 class 1/10 platinum thermistors, whose accuracy is better than $\pm 0.15^{\circ} \mathrm{C}$ at the typical temperatures met during the experiment. Note that, (1) when air temperature $\approx-80^{\circ} \mathrm{C}$, the accuracy degrades to $\pm 0.5^{\circ} \mathrm{C}$, and (2) biases due to radiation contamination may also be an issue. To prevent such biases, the PT100 sensors were not only shielded but also force-ventilated using Young 43502 shields; the sensors were interrogated at 10-s intervals, and averaged on a 30-min timestep. The 30-min data are reported and used in the present study.

Atmospheric moisture is measured using a Humicap capacitive hydroactive Vaisala sensor as a built-in part of the RS92 radiosonde launched at Dome C. They are also used in the Vaisala HMP45ac and HMP155 thermo-hygrometers deployed on the tower. The accuracy is better than $\pm 3 \%$ relative humidity at temperatures about $-40^{\circ} \mathrm{C}$ for values close to saturation.

\section{Diurnal Variations as Observed by HAMSTRAD}

\subsection{Temperature}

Figure 3 shows the diurnal evolution of the monthly-averaged temperature anomaly (difference between the temperature field and its daily average) below $200 \mathrm{~m}$ height above Dome C as measured by the HAMSTRAD microwave radiometer for the months of January to June 2010.

In January 2010 (summertime), the amplitude of the diurnal cycle in temperature is large $( \pm 4 \mathrm{~K}$ ) below $50 \mathrm{~m}$ with a minimum between 0300 and $0400 \mathrm{LST}$ and a maximum $12 \mathrm{~h}$ later between 1500 and 1600 LST. This is consistent with the measurements performed at Dome C by in situ sensors below $45 \mathrm{~m}$ in January 1999 and 2000 (King et al. 2006), and in January 2008 (Genthon et al. 2010). Then, moving upward to $100 \mathrm{~m}$, both minima and maxima appear later, shifted by about $4 \mathrm{~h}$, to 0700-0900 LST and 1900-2100 LST, respectively, with a cycle amplitude much less than that close to the surface, namely \pm 1.5 and $\pm 1.0 \mathrm{~K}$ at 30 and $100 \mathrm{~m}$, respectively. Above $100 \mathrm{~m}$, the diurnal cycle is even weaker $( \pm 1 \mathrm{~K})$ with a minimum amplitude at 0600 LST and a maximum at 2000 LST. 
Dome C: Temperature Anomaly
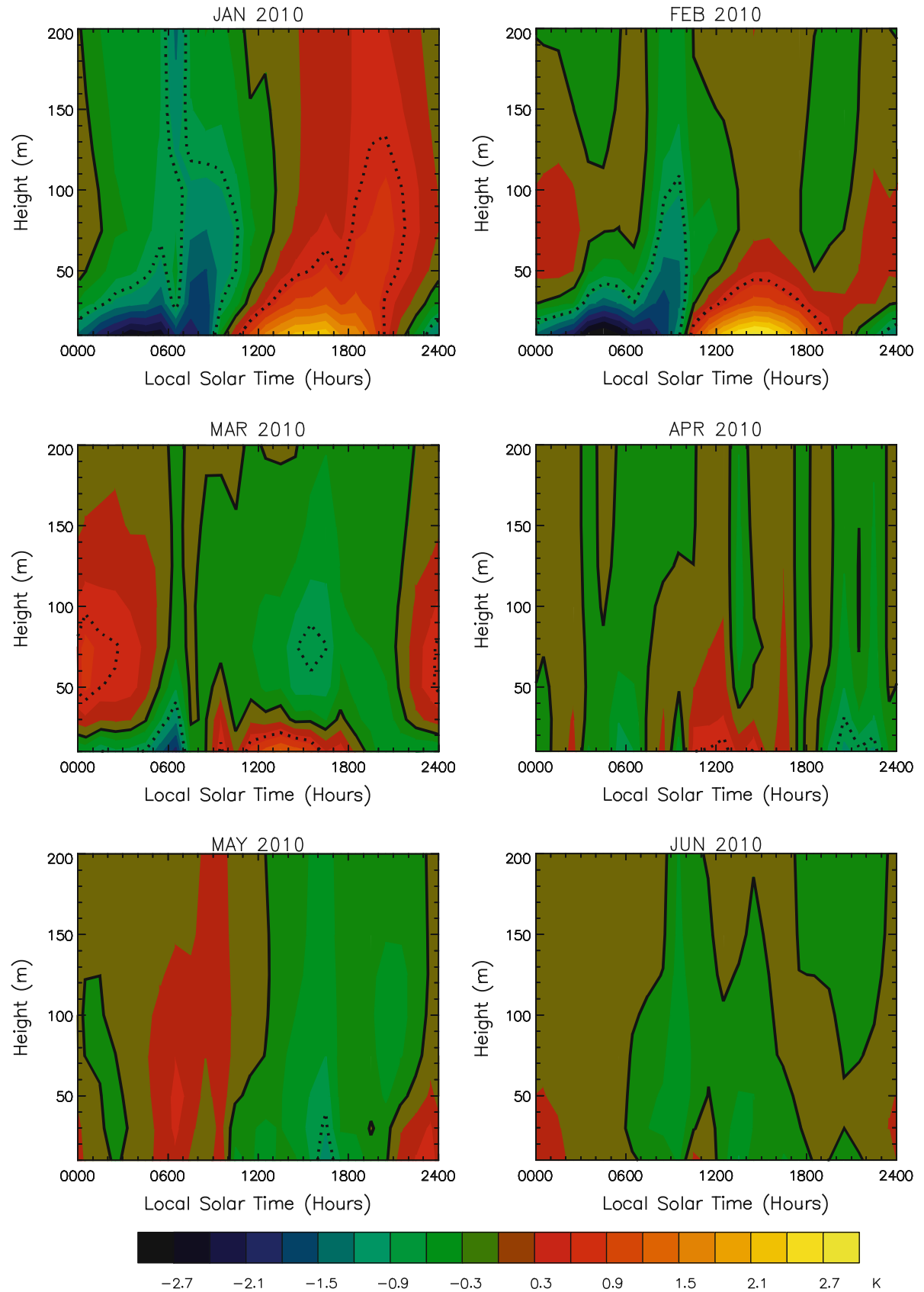

Fig. 3 (From left to right and from top to bottom) Time variation over $24 \mathrm{~h}$ (LST versus height $(0-200 \mathrm{~m})$ ) above the site of the monthly-averaged temperature $(\mathrm{K})$ anomaly (difference between the temperature and its daily average at the same height) as measured by the HAMSTRAD microwave radiometer, for the months of January-June 2010. The black solid line represents an anomaly of zero, and the black dotted lines anomalies of $\pm 0.8 \mathrm{~K}$. Note that, on January 2010 , the temperature anomaly has been estimated from 8 to 31 January 
The maximum incoming shortwave radiation and the minimum in surface albedo are measured occur at 1200 LST (King et al. 2006) at Dome C (Fig. 1), and the maximum temperature above the surface lags solar noon by $2-4 \mathrm{~h}$, in agreement with Genthon et al. (2010). From SOund Detection And Ranging (SODAR) measurements at Dome C (Argentini et al. 2005), the mixed-layer height (PBL top) reaches 200-300 m at 1300-1400 LST in high summer (end of December-early January), and 100-200 m late in the summer (end of January-early February). These SODAR measurements also tend to show a high interannual variability, since during the periods 22-30 January 1998 and 2000, the mean daily mixed-layer height reaches about 140 and $190 \mathrm{~m}$, respectively at 1400-1500 LST. The transition from the PBL (although not actually measured using the SODAR in 2010) to the free troposphere is not associated with any obvious change (in amplitude and/or phase) in the HAMSTRAD monthly-averaged temperature diurnal cycle within the range 100-200 m. Even higher up, in the layer 200-400 $\mathrm{m}$, the temperature anomaly does not differ from the anomaly in the layer 100-200 $\mathrm{m}$ (not shown).

Considering the vertical profiles of potential temperature $(\theta)$ calculated from the radiosondes at 2000 LST in January 2010 (Fig. 4) using a reference pressure of $650 \mathrm{hPa}$ (mean surface pressure at Dome C), we note several points. Firstly, according to the classical representation of the diurnal evolution of the PBL shown in e.g. Stull (1988), the PBL top at 2000 LST should be less well defined than in the middle of the day. Secondly, the top of the PBL, namely the transition between the PBL and the free troposphere as characterized by the entrainment zone where the gradient in $\theta$ is strongly positive within a few metres, is rather well defined for some dates (e.g., 8, 15 and 24 January) and not for others (e.g., 10, 16 and 30 January). Thirdly, the top of the PBL, even when obviously characterized, can vary considerably from one day to another within a very short period: for instance, from $\approx 800 \mathrm{~m}$ on 8 January to $\approx 300 \mathrm{~m}$ on 9 January down to $\approx 100 \mathrm{~m}$ on 25 January. Consequently, the averaging of a month-long temperature dataset, as performed in our analysis, will definitively smear out the transition region, and the top of the PBL will no longer be discernable for the particular month of January.

In February 2010, the diurnal cycle in temperature below $50 \mathrm{~m}$ is very similar to the January 2010 measurements both in amplitude and phase. Between 50 and $100 \mathrm{~m}$, the diurnal cycle ( $\pm 0.7 \mathrm{~K}$ amplitude) drastically differs compared to January. Indeed a wide maximum appears between 2200 and 0300 LST and a weaker maximum still persists at 1400 LST, whilst a strong minimum shows up between 0800 and 0900 LST. Above $100 \mathrm{~m}$, the diurnal amplitude is very weak $(<0.5 \mathrm{~K})$. The transition at $50 \mathrm{~m}$, as marked by a change in amplitude and phase of the diurnal cycle in temperature, can be attributed to the signature of the mean daily mixed-layer height that naturally decreases from January to February because of the lessening of incoming shortwave radiation (Fig. 2). Considering the time evolution of the radiosonde profiles in February 2010 (Fig. 4), the mixed-layer top indeed lowers from $\approx 150 \mathrm{~m}$ on 5 February down to $\approx 50 \mathrm{~m}$ on 16 February, and is no longer discernable by the end of the month.

In March 2010 (autumn), the diurnal cycle is very similar to that measured in February except that the amplitude is smaller $( \pm 2.0 \mathrm{~K})$ near the surface and slightly greater above $( \pm 1 \mathrm{~K})$. A change in the amplitude and phase of the diurnal cycle occurs at around $30 \mathrm{~m}$, i.e. lower than in February. Again, this mimics the lowering of the top of the PBL. In April 2010 (autumn), there is still a non-negligible $( \pm 0.5 \mathrm{~K})$ diurnal signal very close to the surface with a slight minimum around 2200 LST and a wide maximum around and after noon. Thus the PBL is confined below $20 \mathrm{~m}$. The incoming shortwave radiation (Fig. 2) is so low and lasts for such a short time around local noon that it produces a small diurnal cycle amplitude and an almost null phase lag to local noon. In May and June 2010 (winter), the diurnal variation 


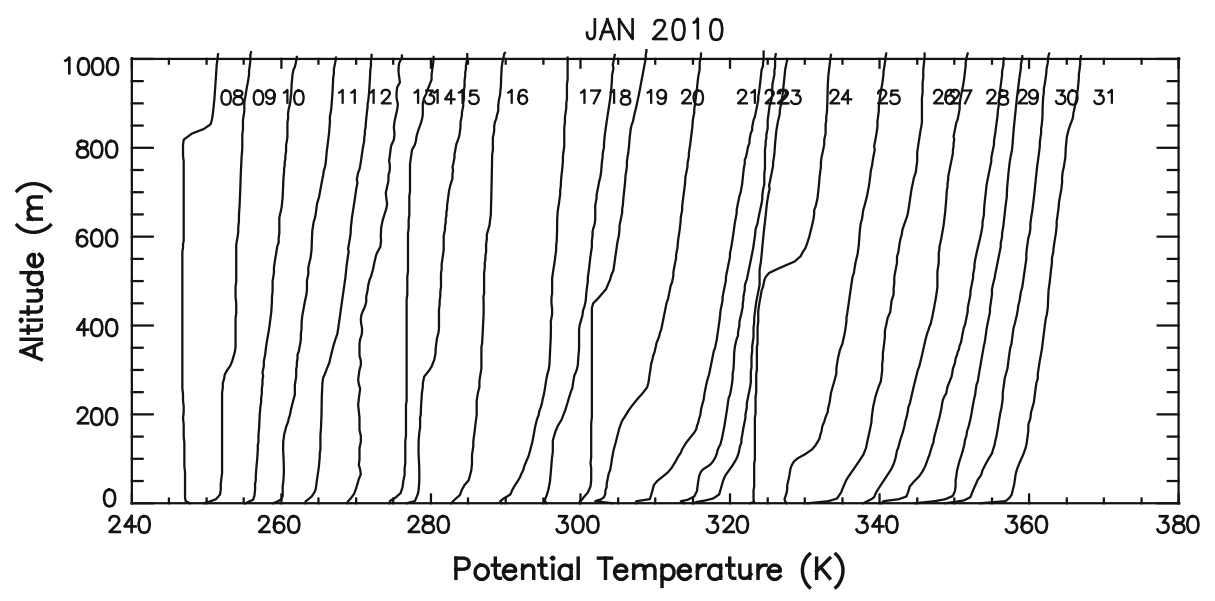

FEB 2010

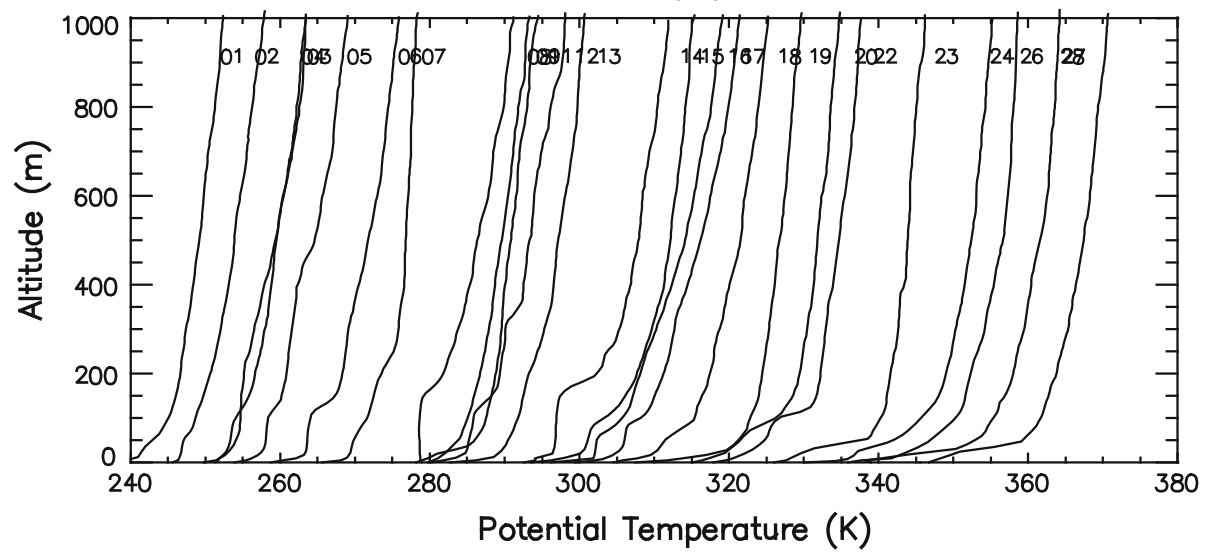

Fig. 4 Day-to-day evolution of the potential temperature as calculated from the radiosondes at 2000 LST from the surface to 1,000 $\mathrm{m}$ in January (top) and February 2010 (bottom). Potential temperatures are calculated with a reference pressure of $650 \mathrm{hPa}$, mean surface pressure at Dome C. For better readability, each profile has been shifted by $+5 \mathrm{~K}$ with respect to the preceding one

in temperature appears to be very noisy, of weak amplitude $(\leq 0.5 \mathrm{~K})$, with no real cycle except a slightly warmer (colder) atmosphere before (after) local noon in May 2010 below $200 \mathrm{~m}$.

\subsection{Water Vapour}

Figure 5 shows the diurnal evolution of the monthly-averaged absolute humidity $\left(\mathrm{g} \mathrm{m}^{-3}\right)$ anomaly (difference between the absolute humidity field and the daily average at the same height) below $200 \mathrm{~m}$ height above Dome $\mathrm{C}$ as measured by the HAMSTRAD microwave radiometer for the months of January to June 2010.

In January 2010, even if the diurnal cycle of absolute humidity as observed by HAMSTRAD is somewhat noisier than the diurnal cycle of temperature because of reduced 

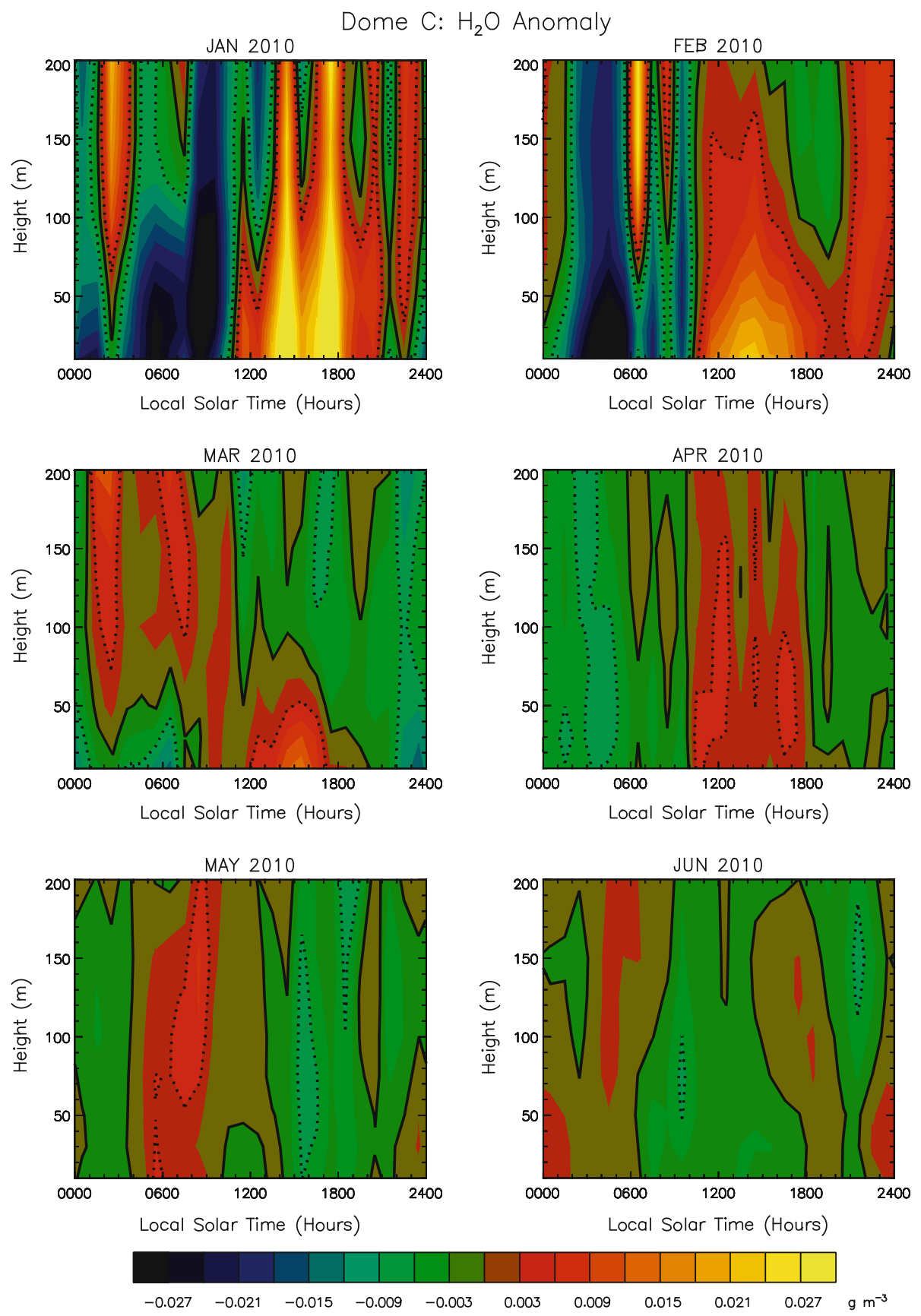

Fig. 5 Same as Fig. 3 but for the absolute humidity $\left(\mathrm{g} \mathrm{m}^{-3}\right)$. The black solid line represents an anomaly of zero, and the black dotted lines anomalies of $\pm 0.006 \mathrm{~g} \mathrm{~m}^{-3}$. Note that, on January 2010, the $\mathrm{H}_{2} \mathrm{O}$ anomaly has been estimated from 16 to 22 January 
statistics (about one week of meaningful measurements), it obviously shows patterns that are highly correlated with the diurnal cycle in temperature. We will quantify the correlation coefficient in Sect. 4.2. In the lowermost troposphere below $50 \mathrm{~m}$, a strong diurnal cycle (amplitude $\pm 0.04 \mathrm{~g} \mathrm{~m}^{-3}$ ) is detected with a wide minimum between 0400 and $0900 \mathrm{LST}$ and a wide maximum between 1300 and 1700 LST. Qualitatively, this is consistent with the in situ sensor measurements performed in 2008 (Genthon et al. 2010). The diurnal cycle extends upward to $100 \mathrm{~m}$ without any phase shift along the vertical as was detected in the temperature field. This is certainly induced by the broader vertical resolution of the $\mathrm{H}_{2} \mathrm{O}$ versus temperature HAMSTRAD measurements (see Appendix). Above $100 \mathrm{~m}$, the diurnal cycle is rather noisy with a slight minimum before local noon and a slight maximum after. In February 2010, the diurnal cycle has a more pronounced minimum around 0400 LST and a wide maximum between 1200 and 1700 LST (amplitude of $\pm 0.03 \mathrm{~g} \mathrm{~m}^{-3}$ ) below $50 \mathrm{~m}$, extending upward to $100 \mathrm{~m}$. Between 100 and $200 \mathrm{~m}$, a local minimum shows up around $1800 \mathrm{LST}$, and consistent with the diurnal cycle in temperature. The peak in $\mathrm{H}_{2} \mathrm{O}$ at 0600 LST from 75 up to $200 \mathrm{~m}$ can be attributed to the contamination on the mean from a few measurements performed on 27 February around 0600 LST showing high amounts of $\mathrm{H}_{2} \mathrm{O}$ from $50 \mathrm{~m}$ increasing in amplitude with height (not shown).

In March 2010, the diurnal cycle amplitude is somehow much smaller $\left( \pm 0.015 \mathrm{~g} \mathrm{~m}^{-3}\right)$ below $20 \mathrm{~m}$ with a minimum at $0600 \mathrm{LST}$ and a maximum at $1500 \mathrm{LST}$ whilst, from 50 to $200 \mathrm{~m}$, the diurnal phase has lagged by almost $12 \mathrm{~h}$, with a minimum between local noon and 1800 LST and a maximum between 0100 and 0600 LST. This phase lag and its evolution with height are consistent with that of the temperature (Fig. 3) except that the phase lag in temperature begins slightly lower in height, namely at $20 \mathrm{~m}$, which again is certainly an imprint of the finer vertical resolution of the temperature profile. In April, HAMSTRAD measures a weak diurnal signal (amplitude $\pm 0.01 \mathrm{~g} \mathrm{~m}^{-3}$ ) with a minimum before 1000 LST and a maximum between 1100 and 1800 LST extending from the surface to the height of $200 \mathrm{~m}$. In May and June, the diurnal variation is very noisy, and presents the same very weak amplitude $\left( \pm 0.004 \mathrm{~g} \mathrm{~m}^{-3}\right)$ for the two months, with no real cycle except a slightly moister (drier) atmosphere before (after) local noon in May below $200 \mathrm{~m}$.

In conclusion, despite the fact that the $\mathrm{H}_{2} \mathrm{O}$ signal is noisier than the temperature signal, particularly in January, HAMSTRAD does measure a diurnal cycle stronger in summer than in winter, with $\mathrm{H}_{2} \mathrm{O}$ and temperature being in phase. In summer, the cycle is stronger in the lowest layers extending upward to $200 \mathrm{~m}$ with a phase lag of $2-4 \mathrm{~h}$. In autumn, two regimes are depicted in March, with an abrupt change in phase of about $12 \mathrm{~h}$ around the height of $50 \mathrm{~m}$ for temperature and $\mathrm{H}_{2} \mathrm{O}$ whilst, in April, there is no obvious imprint of the transition on the temperature and $\mathrm{H}_{2} \mathrm{O}$ cycles. In winter, the amplitude of the diurnal cycle is very weak below $200 \mathrm{~m}$, and can be attributed rather to an imprint of the propagation of air masses of different origins over the station (sampling effect) than to a change induced by solar radiation since the shortwave flux is close to zero at that time.

\section{Assessing the Quality of the Diurnal Variations Observed by HAMSTRAD}

\subsection{Vertical Profiles}

We are now interested in assessing the quality of the temperature and absolute humidity profiles observed by HAMSTRAD from January to June at Dome C. We thus compare 
monthly-averaged values of HAMSTRAD, in situ and radiosonde measurements, and of analyses from the ECMWF model.

\subsubsection{Temperature}

Figure 6 shows, for the months from January to June, the monthly-averaged vertical profiles of temperature, (1) measured by HAMSTRAD (below $200 \mathrm{~m}$ ) and in situ sensors (below $50 \mathrm{~m}$ ), sorted out in 241 -h bins (but for improved clarity only four bins at 0200, 0800, 1400 and 2000 LST are shown); (2) from ECMWF analyses at 0200, 0800, 1400 and 2000 LST; and (3) measured by the radiosondes released at 2000 LST.

In January (summer), the diurnal variability in temperature is greater below $100 \mathrm{~m}( \pm 5 \mathrm{~K})$ than above $( \pm 2 \mathrm{~K})$, both in the HAMSTRAD measurements and in the ECMWF analyses. Below $50 \mathrm{~m}$, the in situ, HAMSTRAD and ECMWF values tend to track the same variability. At 2000 LST, the radiosonde profile shows almost constant values whilst the HAMSTRAD profile exhibits more variability. Indeed, whatever the period considered, HAMSTRAD profiles show a systematic bump of $0.25-0.50 \mathrm{~K}$ between 50 and $100 \mathrm{~m}$, which is present neither in the ECMWF nor in the radiosonde profiles, nor even in the radiosonde measurements that were performed on 24-25 January 2004 at Dome C by Hudson and Brandt (2005) (although these authors have detected a bump higher up between 200 and $250 \mathrm{~m}$ on a single profile at $1600 \mathrm{LST}$ ). At $1400 \mathrm{LST}$ and below $50 \mathrm{~m}$, a gradient of about $-0.04 \mathrm{~K} \mathrm{~m}^{-1}$ is also observed in the HAMSTRAD profiles. The ECMWF and in situ profiles also tend to show below $50 \mathrm{~m}$ such a negative but weaker gradient $\left(\geq-0.02 \mathrm{~K} \mathrm{~m}^{-1}\right)$. Superadiabatic profiles were already observed at Dome $\mathrm{C}$ very close to the surface in the afternoon, from tower data (Genthon et al. 2010; Argentini et al. 2005) and radiosonde data (Hudson and Brandt 2005). Below 50 $\mathrm{m}$, the superadiabatic lapse rates deduced from the HAMSTRAD measurements appear to be rather consistent with those deduced from all the other datasets. In February, all datasets are very consistent, both in the vertical and in the diurnal variability, with a temperature minimum close to the surface and increasing with height; the ECMWF profiles below $50 \mathrm{~m}$ at $1400 \mathrm{LST}$, however, show higher temperatures than the HAMSTRAD profiles and in situ ones. As in January, the diurnal variability is much greater $( \pm 4 \mathrm{~K})$ below $50 \mathrm{~m}$ than above $( \pm 1 \mathrm{~K})$.

Entering the autumn in March, the diurnal variability lessens in amplitude ( $\pm 2-3 \mathrm{~K})$ from 10 to $200 \mathrm{~m}$. Some systematic differences show up between the datasets, except between the radiosonde and HAMSTRAD profiles that are very similar. Indeed, the ECMWF profiles have temperatures $1-3 \mathrm{~K}$ lower than the radiosonde profiles and HAMSTRAD profiles in the 50-100 m layer. This feature becomes even more obvious when moving to the winter. In April, the diurnal cycle is indeed becoming weaker (as already mentioned in the previous section), the radiosonde, the in situ and the HAMSTRAD profiles agree very well except at $10 \mathrm{~m}$ where radiosonde and in situ temperatures are much lower than for HAMSTRAD by about $3 \mathrm{~K}$. Below $120 \mathrm{~m}$, the ECMWF profiles, as in March, systematically tend to be $2-4 \mathrm{~K}$ colder than radiosonde and HAMSTRAD profiles.

In May (winter), some systematic differences show up, namely a steeper gradient below $50 \mathrm{~m}$ on the radiosonde and in situ profiles, compared to HAMSTRAD ones. The ECMWF profiles are all much colder $(2-5 \mathrm{~K})$ than the radiosonde and HAMSTRAD profiles below $150 \mathrm{~m}$, but have a gradient similar to that of HAMSTRAD. The tendency of HAMSTRAD to smooth the steepness of the temperature vertical gradient as observed on all the other datasets below $50 \mathrm{~m}$ arises from the vertical resolution of the microwave instrument, which is about 10-20 m (see Appendix). In June, the datasets are very consistent altogether above $120 \mathrm{~m}$, 

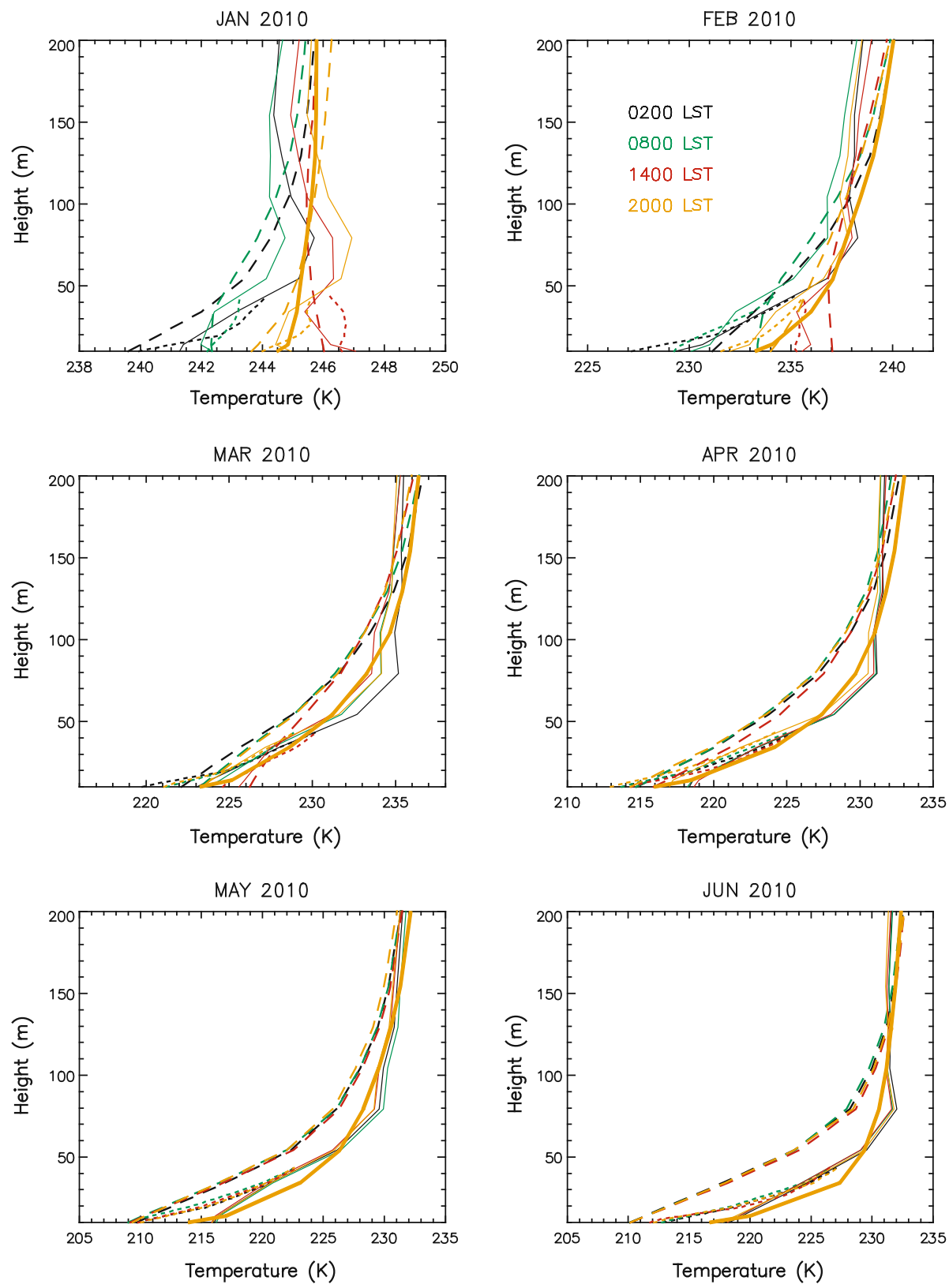

Fig. 6 (From left to right and from top to bottom) Monthly-averaged vertical profiles of temperature (K) sorted out into 24 1-h bins for the months of January-June 2010, as measured by the HAMSTRAD microwave radiometer (coloured solid line), by the in situ sensors (coloured dotted line), as outputs from the ECMWF analyses (coloured dashed line) at four selected LSTs (0200, 0800, 1400 and 2000) and as measured by the radiosonde at 2000 LST (coloured thick solid line). The colour scale (from dark blue at 0200 LST to yellow at 2000 LST) is shown on the February plots. Note that, on January 2010, the temperature profiles from HAMSTRAD, radiosonde and ECMWF have been averaged from 8 to 31 January 
whilst below, the differences underlined in May are accentuated. The radiosonde and in situ profiles below $50 \mathrm{~m}$ are much steeper than those of ECMWF and HAMSTRAD.

In conclusion, the HAMSTRAD vertical profiles and diurnal variabilities in temperature are very consistent with in situ, radiosonde and ECMWF data during the summer. From March to June, whatever the time, HAMSTRAD profiles mimic in situ and radiosonde profiles, whereas ECMWF profiles are systematically colder than the other datasets. Below 50 $\mathrm{m}$, the vertical resolution of the HAMSTRAD temperature measurements (10-20 m) tends to smooth the steepness of the vertical profiles in winter, with respect to in situ and radiosonde profiles.

\subsubsection{Water Vapour}

Figure 7 shows, for the months from January to June, the monthly-averaged vertical profiles of absolute humidity, (1) measured by HAMSTRAD (below $200 \mathrm{~m}$ ) and the in situ sensors (below $50 \mathrm{~m}$ ), sorted out in 241 -h bins (but for better readability only four bins at 0200, 0800, 1400 and 2000 LST are shown); (2) from ECMWF analyses at 0200, 0800, 1400 and 2000 LST; and (3) measured by the radiosondes released at 2000 LST. Because the HAMSTRAD measurements tend to show a much moister atmosphere compared to all the other datasets, the HAMSTRAD vertical profiles of absolute humidity have been shifted by an arbitrary amount $\left(\Delta_{\mathrm{H}}\right)$, independent of the height, and evolving from $\Delta_{\mathrm{H}}=-0.2 \mathrm{~g} \mathrm{~m}^{-3}$ in summer to $\Delta_{\mathrm{H}}=-0.05 \mathrm{~g} \mathrm{~m}^{-3}$ in winter.

In January, the vertical distribution of the absolute humidity and its diurnal cycle as observed by HAMSTRAD significantly differ from the radiosonde, the in situ and the ECMWF datasets. The diurnal amplitude along the vertical below $200 \mathrm{~m}$ is almost constant (about $\pm 0.04 \mathrm{~g} \mathrm{~m}^{-3}$ ) in the HAMSTRAD datasets, whilst it is much higher below $50 \mathrm{~m}$ on both the in situ data $\left( \pm 0.12 \mathrm{~g} \mathrm{~m}^{-3}\right)$ and the ECMWF analyses $\left( \pm 0.08 \mathrm{~g} \mathrm{~m}^{-3}\right)$. For the latter, it decreases above, down to zero at $150 \mathrm{~m}$. There is a positive gradient in the HAMSTRAD dataset below $150 \mathrm{~m}$ whilst it is more constrained below $30 \mathrm{~m}$ in the radiosonde dataset and below $50-100 \mathrm{~m}$ in the ECMWF analyses. This is certainly due to the vertical resolution of the HAMSTRAD $\mathrm{H}_{2} \mathrm{O}$ measurements $(25-50 \mathrm{~m})$, which cannot capture the steepness of the actual gradient below $50 \mathrm{~m}$ altitude.

The amount of $\mathrm{H}_{2} \mathrm{O}$ measured by HAMSTRAD is about $0.1-0.2 \mathrm{~g} \mathrm{~m}^{-3}$ greater than in the radiosonde and in situ datasets, which are also moister than the ECMWF analyses by $0.05 \mathrm{~g} \mathrm{~m}^{-3}$. This positive bias observed in the HAMSTRAD $\mathrm{H}_{2} \mathrm{O}$ dataset is very consistent with the conclusions of the validation process performed using the January-February 2009 measurements in comparison with radiosonde, in situ and satellite datasets (Ricaud et al. 2011). The HAMSTRAD $\mathrm{H}_{2} \mathrm{O}$ amounts are not only moist biased but are also unrealistic, corresponding to relative humidity that may be greater than $100 \%$. Comparisons with other datasets (in situ, space-borne, analyses, etc.) in 2009 and 2010 (Tremblin et al. 2011) tend to show that the integrated water vapour (IWV) from HAMSTRAD is not biased by more than $5 \%$. This implies that the calibration of the HAMSTRAD microwave radiometer is correctly performed. Indeed, when considering HAMSTRAD tropospheric $\mathrm{H}_{2} \mathrm{O}$ profiles, we have observed that the moist bias did not extend throughout the troposphere but showed a significant dry bias at high altitudes to offset it (Ricaud et al. 2011; Carminati et al. 2011b, manuscript in preparation). Consequently, the minimization of this strong positive bias in the lowermost troposphere is nowadays under study by developing a linear regression retrieval method based upon a set of four years of radiosondes launched at Dome C. Indeed, the presently used regression method has been developed by using radiosonde profiles launched at 

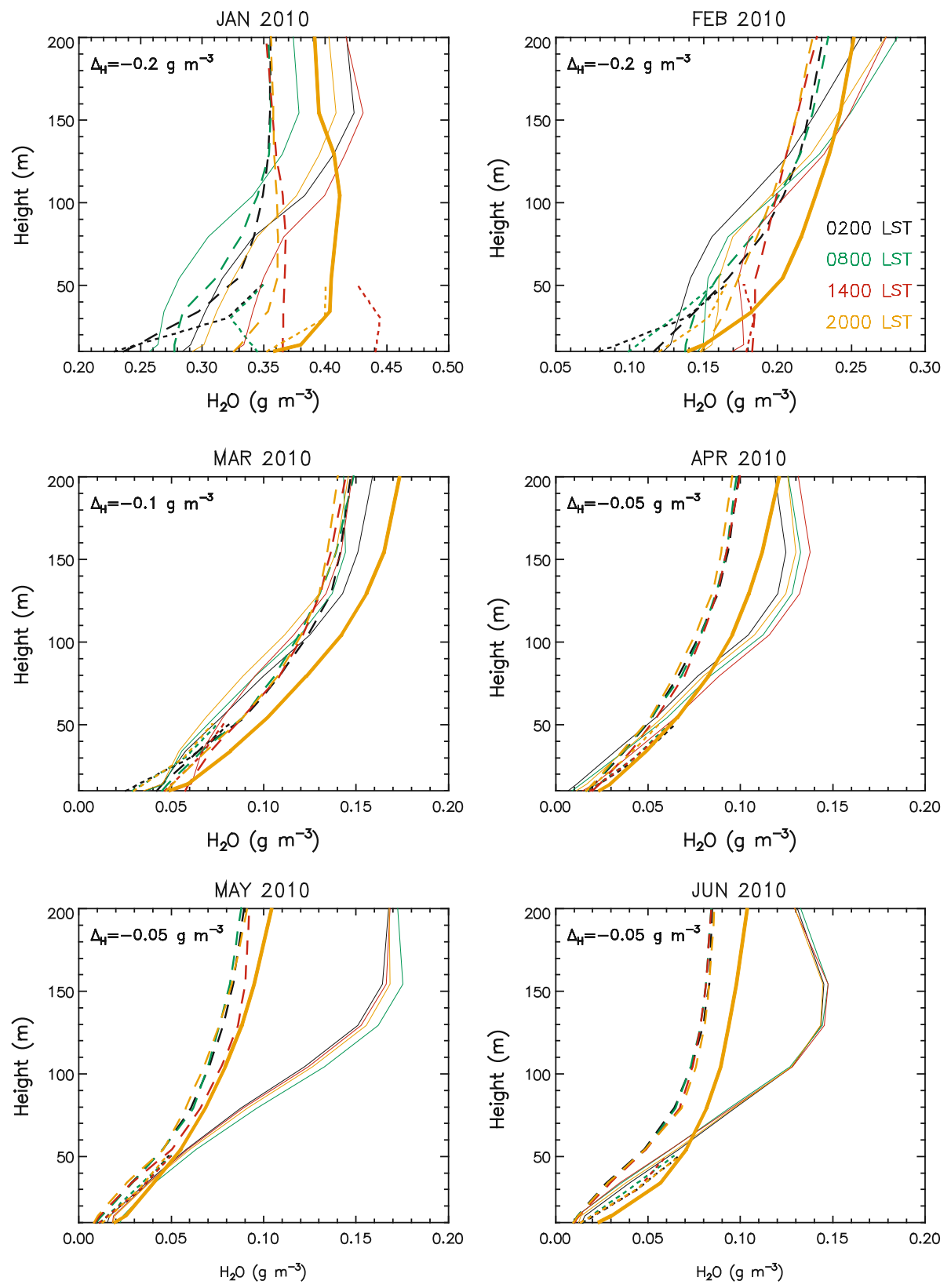

Fig. 7 Same as Fig. 6 but for the absolute humidity $\left(\mathrm{g} \mathrm{m}^{-3}\right)$. For better readability along the $x$-axis and because the HAMSTRAD measurements tend to show a much moister atmosphere compared to the other datasets, the HAMSTRAD vertical profiles of absolute humidity have been shifted by an arbitrary amount $\left(\Delta_{\mathrm{H}}\right)$ constant along the vertical but dependent on the considered month. The shift $\Delta_{\mathrm{H}}$ is shown on each figure. Note that, on January 2010, the $\mathrm{H}_{2} \mathrm{O}$ profiles from HAMSTRAD, radiosonde and ECMWF have been averaged from 16 to 22 January 
the South Pole and the McMurdo stations in Antarctica, namely in atmospheric conditions that may significantly differ from those encountered at Dome C.

In February, the diurnal cycle is less intense than in January in all HAMSTRAD $\left( \pm 0.03 \mathrm{~g} \mathrm{~m}^{-3}\right)$, in situ $\left( \pm 0.07 \mathrm{~g} \mathrm{~m}^{-3}\right)$, and ECMWF $\left( \pm 0.04 \mathrm{~g} \mathrm{~m}^{-3}\right)$ datasets, and extends up to $200 \mathrm{~m}$ on HAMSTRAD profiles but only up to $100 \mathrm{~m}$ on ECMWF profiles. The radiosonde $\mathrm{H}_{2} \mathrm{O}$ amounts are slightly greater than ECMWF amounts (by $0.03 \mathrm{~g} \mathrm{~m}^{-3}$ ) but much less than the HAMSTRAD amounts (by about $0.1-0.2 \mathrm{~g} \mathrm{~m}^{-3}$ ). The vertical profiles of the various datasets are consistent with each other below $100 \mathrm{~m}$ whilst above, the radiosonde and ECMWF vertical gradients are slightly smoother than the HAMSTRAD ones. Again, as in January, the imprint of the vertical resolution of the HAMSTRAD $\mathrm{H}_{2} \mathrm{O}$ measurements $(25-50 \mathrm{~m})$ on the vertical distribution of the diurnal variation is obviously highlighted.

From autumn to winter (March to June), the HAMSTRAD $\mathrm{H}_{2} \mathrm{O}$ amounts are systematically much greater than the radiosonde and ECMWF amounts by $0.05-0.1 \mathrm{~g} \mathrm{~m}^{-3}$, with the ECMWF values slightly but systematically drier than radiosonde and in situ measurements. Except in March, the vertical gradients appear to be much smoother in the radiosonde and ECMWF datasets than in the HAMSTRAD dataset, with a net maximum around the height of $150 \mathrm{~m}$ that is not present in any of the other datasets. Finally, the diurnal cycle is extremely weak $\left( \pm 0.02 \mathrm{~g} \mathrm{~m}^{-3}\right)$ in the HAMSTRAD data and almost null in the ECMWF analyses and in situ data.

In conclusion, HAMSTRAD $\mathrm{H}_{2} \mathrm{O}$ profiles are systematically and unrealistically much moister than ECMWF, in situ and radiosonde profiles whatever the time of day and the seasons considered. The diurnal cycle in $\mathrm{H}_{2} \mathrm{O}$ as observed by HAMSTRAD below $200 \mathrm{~m}$ decreases from summer to winter, as in the ECMWF analyses and in situ data, but with an amplitude much smaller in the HAMSTRAD dataset than in the ECMWF and the in situ datasets. Below $50 \mathrm{~m}$, the vertical resolution of the HAMSTRAD $\mathrm{H}_{2} \mathrm{O}$ measurements (25$50 \mathrm{~m}$ ) tends to smooth the steepness of the vertical profiles in all the seasons compared to all the other datasets.

\subsection{Diurnal Variations at Fixed Heights}

Now we wish to consider in detail the fine structures of the diurnal cycles in temperature and $\mathrm{H}_{2} \mathrm{O}$ observed by HAMSTRAD, in situ sensors and analyzed by the ECMWF model. Figures 8, 9, 10 show, on the left-hand side, the diurnal variation of the monthly-averaged temperature measured by HAMSTRAD at the retrieval heights from 10 to $200 \mathrm{~m}$ above the surface in summer (January), autumn (March) and winter (June), respectively. Superimposed are the monthly-averaged fields from the ECMWF analyses interpolated onto the same heights at 0200, 0800, 1400 and 2000 LST, together with the in situ measurements interpolated at the same heights and sorted out into 24 1-h bins. On the right-hand side, Figs. 8, 9, 10 show, in a similar way, the monthly-averaged diurnal variations of absolute humidity. We also show, for each month, the HAMSTRAD-ECMWF $\left(\Delta_{\mathrm{H}-\mathrm{E}}\right)$ and the HAMSTRAD-in situ $\left(\Delta_{\mathrm{H}-\mathrm{I}}\right)$ biases, together with the standard deviation of the HAMSTRAD data $\left(\sigma_{\mathrm{H}}\right)$ within the monthly-averaged diurnal variation for temperature and $\mathrm{H}_{2} \mathrm{O}$ in Tables 1 and 2, respectively. Note that ECMWF (in situ) data have been debiased against HAMSTRAD data using $\left(\Delta_{\mathrm{H}-\mathrm{E}}\right)\left(\left(\Delta_{\mathrm{H}-\mathrm{I}}\right)\right)$ listed in Tables 1 and 2 for temperature and $\mathrm{H}_{2} \mathrm{O}$, respectively. Also note that at $10 \mathrm{~m}$, in January only, the $\mathrm{H}_{2} \mathrm{O}$ diurnal amplitude on the ECMWF and in situ data has been multiplied by 0.25 to cope with the HAMSTRAD weak variability along the $y$-axis. Finally, we present the temperature- $\mathrm{H}_{2} \mathrm{O}$ correlation coefficient in the HAMSTRAD $\left(r_{\mathrm{H}}\right)$ and the in situ $\left(r_{\mathrm{I}}\right)$ monthly-mean hourly values in Table 3 for the period January-June. 

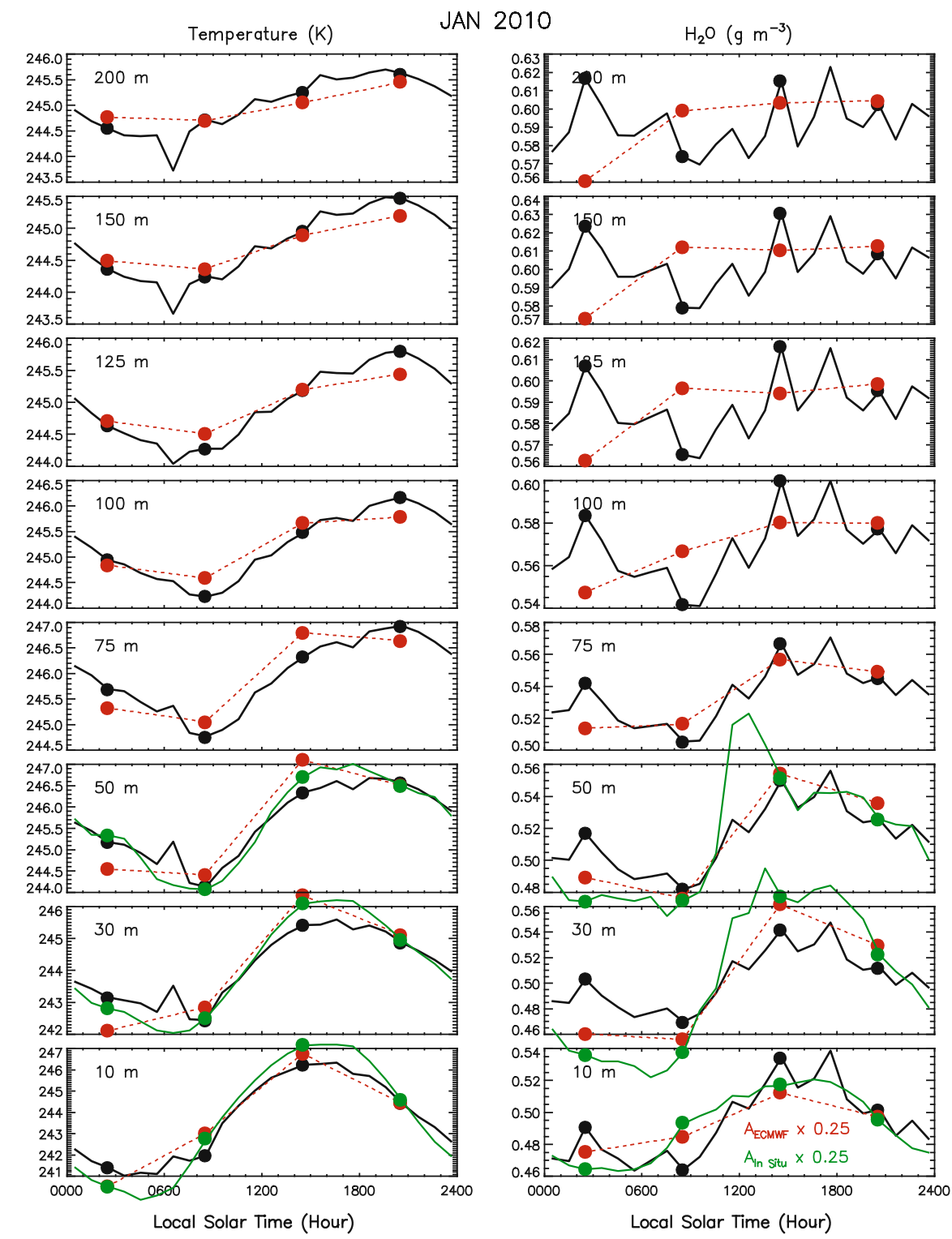

Fig. 8 (Left, from bottom to top) Time variation of monthly-averaged temperature (K) from 10 to $200 \mathrm{~m}$ height above the site, at $30,50,75,100,125$ and $150 \mathrm{~m}$, as measured by the HAMSTRAD microwave radiometer (black solid lines) over $24 \mathrm{~h}$, the in situ sensors (green solid lines) over $24 \mathrm{~h}$ and as outputs from the ECMWF analyses (red solid circles and dotted lines) at 0200, 0800, 1400 and 2000 LST, for the month of January 2010. We have also highlighted the HAMSTRAD and in situ measurements at 0200, 0800, 1400 and 2000 LST for a better comparison in coincidence with the ECMWF outputs. ECMWF and in situ data have been debiased against HAMSTRAD data using biases listed in Table 1. (Right, from bottom to top) Same as the left-hand side of the figure, but for absolute humidity $\left(\mathrm{g} \mathrm{m}^{-3}\right)$. ECMWF and in situ data have been debiased against HAMSTRAD data using biases listed in Table 2. Note that, in January 2010, the HAMSTRAD, in situ and ECMWF temperature and $\mathrm{H}_{2} \mathrm{O}$ profiles have been averaged from 8 to 31 January, and from 16 to 22 January, respectively. Finally, at $10 \mathrm{~m}$, the diurnal amplitudes of the $\mathrm{H}_{2} \mathrm{O}$ ECMWF $\left(A_{\text {ECMWF }}\right)$ and in situ $\left(A_{\text {In Situ }}\right)$ sensors have been divided by 4 to cope with the weak HAMSTRAD variability along the $y$-axis 

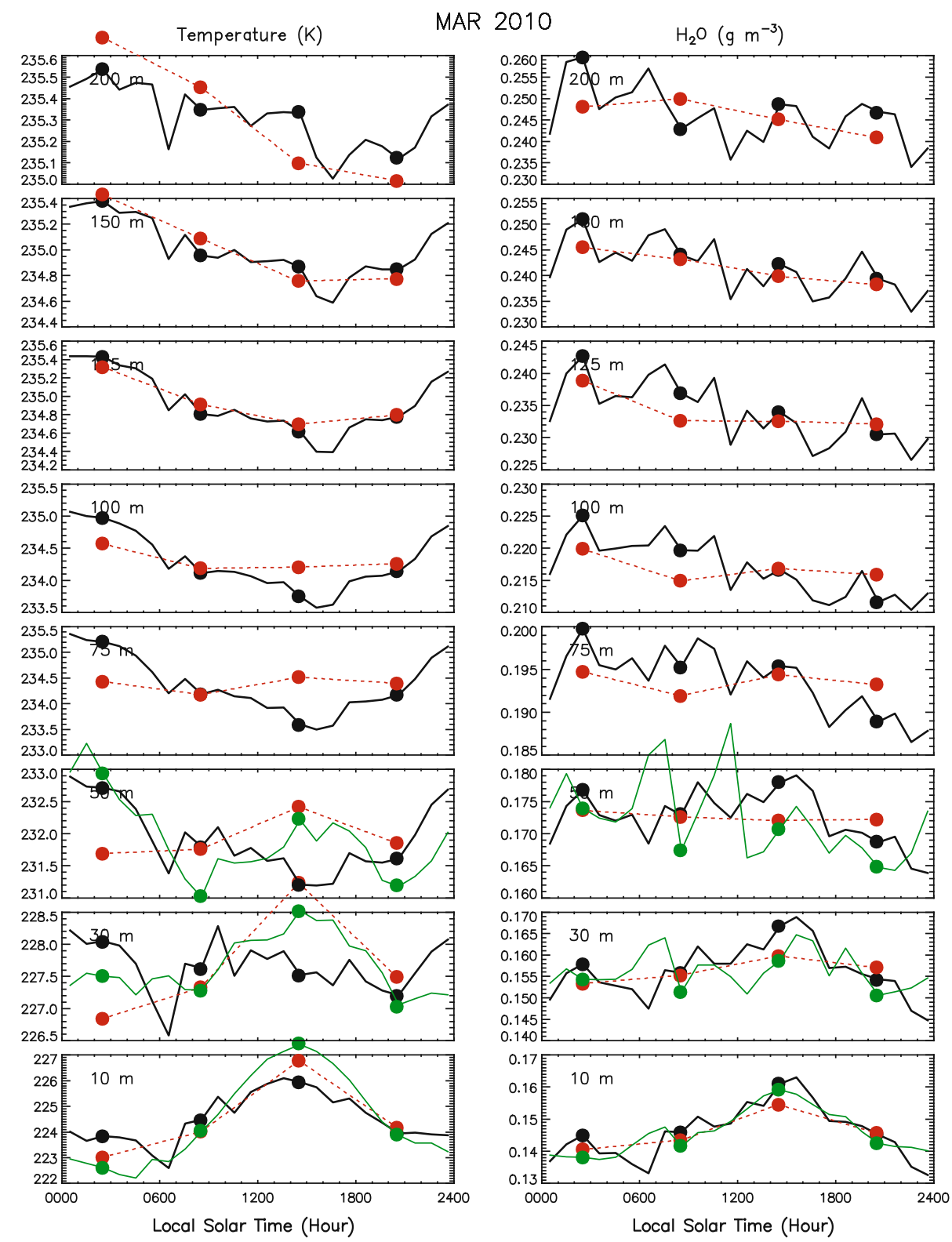

Fig. 9 Same as Fig. 8, but for March 2010, except that $\mathrm{H}_{2} \mathrm{O}$ ECMWF and in situ diurnal amplitudes at $10 \mathrm{~m}$ have not been divided by 4

The diurnal cycles in temperature and $\mathrm{H}_{2} \mathrm{O}$ from both HAMSTRAD and ECMWF data in summer (January) below $200 \mathrm{~m}$, and from HAMSTRAD and in situ sensors below $50 \mathrm{~m}$, are in very good agreement, except for the amplitude of the $\mathrm{H}_{2} \mathrm{O}$ cycle at $10 \mathrm{~m}$, which is four times greater in ECMWF and in situ data than in HAMSTRAD data (Fig. 8). The 4-h phase lag in temperature diurnal cycle between 10 and $200 \mathrm{~m}$ heights, observed by HAMSTRAD, is well 

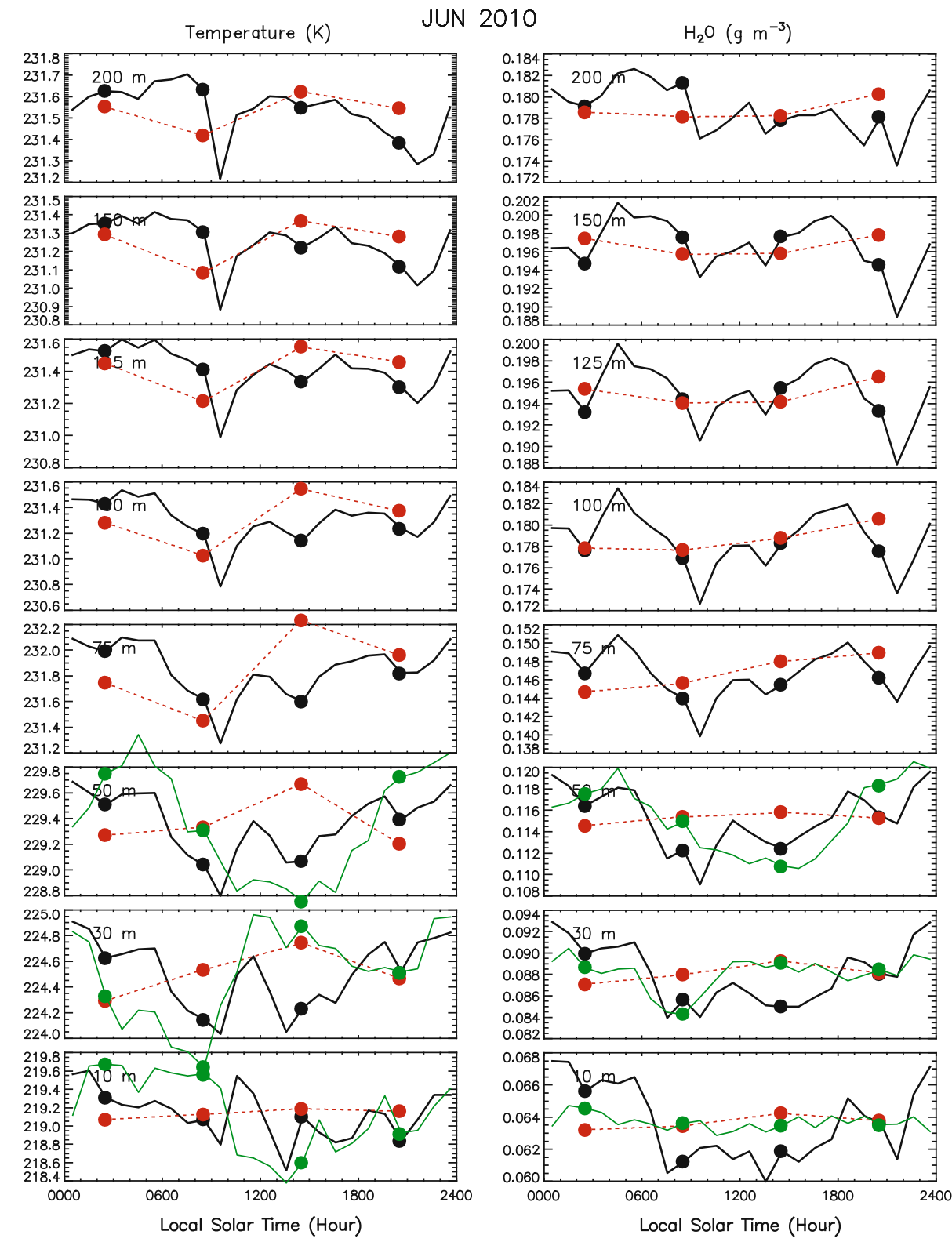

Fig. 10 Same as Fig. 8 but for June 2010, except that $\mathrm{H}_{2} \mathrm{O}$ ECMWF and in situ diurnal amplitudes at $10 \mathrm{~m}$ have not been divided by 4

reproduced in ECMWF analyses. Below $100 \mathrm{~m}$, the diurnal cycle in $\mathrm{H}_{2} \mathrm{O}$ in HAMSTRAD data is also well reproduced by ECMWF analyses and in situ data but above, the slight minimum measured around 0800 LST is not present in the analyses. The strong correlation (better than 0.80 ) between temperature and $\mathrm{H}_{2} \mathrm{O}$ observed below $50 \mathrm{~m}$ on HAMSTRAD and in situ datasets is less obvious above (correlation ranges 0.2-0.6). Such a high correlation 
Table 1 Standard deviation of the HAMSTRAD temperature $(\mathrm{K})$ measurements $\left(\sigma_{\mathrm{H}}\right)$, HAMSTRADECMWF bias $\left(\Delta_{\mathrm{H}-\mathrm{E}}\right.$, difference between the daily averaged values of temperature from HAMSTRAD and ECMWF) and the HAMSTRAD-in situ bias $\left(\Delta_{\mathrm{H}-\mathrm{I}}\right)$ depending on the month from January to June 2010 , and the height at $10,30,50,75,100,125,150$ and $200 \mathrm{~m}$

\begin{tabular}{|c|c|c|c|c|c|c|c|c|}
\hline & \multicolumn{8}{|c|}{ Height } \\
\hline & $10 \mathrm{~m}$ & $30 \mathrm{~m}$ & $50 \mathrm{~m}$ & $75 \mathrm{~m}$ & $100 \mathrm{~m}$ & $125 \mathrm{~m}$ & $150 \mathrm{~m}$ & $200 \mathrm{~m}$ \\
\hline \multicolumn{9}{|l|}{ January } \\
\hline$\sigma_{\mathrm{H}}$ & 1.8 & 1.7 & 1.6 & 1.6 & 1.6 & 1.6 & 1.7 & 1.7 \\
\hline$\Delta_{\mathrm{H}-\mathrm{E}}$ & 0.5 & 0.3 & 1.2 & 1.0 & -0.1 & -0.7 & -1.2 & -1.2 \\
\hline$\Delta_{\mathrm{H}-\mathrm{I}}$ & 0.6 & -0.6 & 0.8 & NA & NA & NA & NA & NA \\
\hline \multicolumn{9}{|l|}{ February } \\
\hline$\sigma_{\mathrm{H}}$ & 5.0 & 4.7 & 4.5 & 4.4 & 4.2 & 3.9 & 3.7 & 3.5 \\
\hline$\Delta_{\mathrm{H}-\mathrm{E}}$ & -1.3 & -0.8 & 0.9 & 1.1 & -0.1 & -0.5 & -1.0 & -1.2 \\
\hline$\Delta_{\mathrm{H}-\mathrm{I}}$ & 1.8 & -0.1 & 0.8 & NA & NA & NA & NA & NA \\
\hline \multicolumn{9}{|l|}{ March } \\
\hline$\sigma_{\mathrm{H}}$ & 6.6 & 6.1 & 5.3 & 4.5 & 4.0 & 3.5 & 3.4 & 3.4 \\
\hline$\Delta_{\mathrm{H}-\mathrm{E}}$ & 0.3 & 1.1 & 2.9 & 2.8 & 1.1 & 0.4 & -0.3 & -1.1 \\
\hline$\Delta_{\mathrm{H}-\mathrm{I}}$ & 2.8 & 0.3 & 1.2 & NA & NA & NA & NA & NA \\
\hline \multicolumn{9}{|l|}{ April } \\
\hline$\sigma_{\mathrm{H}}$ & 8.1 & 7.3 & 6.3 & 5.6 & 5.0 & 4.6 & 4.3 & 4.1 \\
\hline$\Delta_{\mathrm{H}-\mathrm{E}}$ & 2.3 & 2.4 & 4.2 & 3.9 & 1.8 & 0.8 & -0.1 & -0.9 \\
\hline$\Delta_{\mathrm{H}-\mathrm{I}}$ & 4.4 & 1.1 & 1.4 & NA & NA & NA & NA & NA \\
\hline \multicolumn{9}{|l|}{ May } \\
\hline$\sigma_{\mathrm{H}}$ & 8.0 & 7.5 & 6.7 & 5.7 & 5.1 & 4.4 & 4.1 & 3.8 \\
\hline$\Delta_{\mathrm{H}-\mathrm{E}}$ & 5.9 & 4.2 & 4.0 & 3.6 & 1.9 & 1.3 & 0.6 & 0.1 \\
\hline$\Delta_{\mathrm{H}-\mathrm{I}}$ & 6.7 & 1.9 & 1.7 & NA & NA & NA & NA & NA \\
\hline \multicolumn{9}{|l|}{ June } \\
\hline$\sigma_{\mathrm{H}}$ & 6.8 & 5.2 & 4.3 & 3.9 & 3.7 & 3.5 & 3.4 & 3.3 \\
\hline$\Delta_{\mathrm{H}-\mathrm{E}}$ & 7.7 & 6.7 & 5.6 & 3.6 & 1.2 & 0.2 & -0.6 & -1.1 \\
\hline$\Delta_{\mathrm{H}-\mathrm{I}}$ & 6.8 & 1.1 & 1.1 & NA & NA & NA & NA & NA \\
\hline
\end{tabular}

$\mathrm{NA}=$ not available

below $50 \mathrm{~m}$ results partly from the fact that the saturation vapour pressure increases with temperature. Thus the water-holding capacity of the air correlates with temperature. At $10 \mathrm{~m}$ height, a positive bias is observed for both the temperature $\left(\Delta_{\mathrm{H}-\mathrm{E}}\right.$ and $\left.\Delta_{\mathrm{H}-\mathrm{I}} \approx 0.5 \mathrm{~K}\right)$ and $\mathrm{H}_{2} \mathrm{O}\left(\Delta_{\mathrm{H}-\mathrm{E}}\right.$ and $\left.\Delta_{\mathrm{H}-\mathrm{I}} \approx 0.15 \mathrm{~g} \mathrm{~m}^{-3}\right)$. Note that above $100 \mathrm{~m}$, the amplitude of the temperature and $\mathrm{H}_{2} \mathrm{O}$ cycles is less than, or of the order of, the standard deviation of the HAMSTRAD dataset (namely, $\sigma_{\mathrm{H}} \approx 1.6 \mathrm{~K}$ and $\approx 0.08 \mathrm{~g} \mathrm{~m}^{-3}$, respectively), and conversely below $100 \mathrm{~m}$.

In autumn (March), the diurnal cycles in temperature as observed by HAMSTRAD, from the ECMWF analyses and in situ measurements, are in very good agreement at $10 \mathrm{~m}$ height (Fig. 9). Above, in the 100-200 m layer, HAMSTRAD and ECMWF data agree well. In the transition layer (30-75 m), the measured and analyzed diurnal cycles appear to be outof-phase by about $12 \mathrm{~h}$, as if the transition between the two opposite cycles (at the lowest heights and at $200 \mathrm{~m}$ height) did not coincide in the HAMSTRAD dataset on the one hand, 
Table 2 Same as Table 1 , but for absolute humidity $\left(\mathrm{g} \mathrm{m}^{-3}\right)$

\begin{tabular}{|c|c|c|c|c|c|c|c|c|}
\hline & \multicolumn{8}{|l|}{ Height } \\
\hline & $10 \mathrm{~m}$ & $30 \mathrm{~m}$ & $50 \mathrm{~m}$ & $75 \mathrm{~m}$ & $100 \mathrm{~m}$ & $125 \mathrm{~m}$ & $150 \mathrm{~m}$ & $200 \mathrm{~m}$ \\
\hline \multicolumn{9}{|l|}{ January } \\
\hline$\sigma_{\mathrm{H}}$ & 0.070 & 0.068 & 0.063 & 0.063 & 0.075 & 0.083 & 0.090 & 0.097 \\
\hline$\Delta_{\mathrm{H}-\mathrm{E}}$ & 0.160 & 0.148 & 0.145 & 0.152 & 0.178 & 0.191 & 0.201 & 0.186 \\
\hline$\Delta_{\mathrm{H}-\mathrm{I}}$ & 0.152 & 0.122 & 0.125 & NA & NA & NA & NA & NA \\
\hline \multicolumn{9}{|l|}{ February } \\
\hline$\sigma_{\mathrm{H}}$ & 0.108 & 0.112 & 0.112 & 0.115 & 0.125 & 0.125 & 0.126 & 0.118 \\
\hline$\Delta_{\mathrm{H}-\mathrm{E}}$ & 0.202 & 0.194 & 0.184 & 0.180 & 0.194 & 0.211 & 0.223 & 0.244 \\
\hline$\Delta_{\mathrm{H}-\mathrm{I}}$ & 0.231 & 0.203 & 0.191 & NA & NA & NA & NA & NA \\
\hline \multicolumn{9}{|l|}{ March } \\
\hline$\sigma_{\mathrm{H}}$ & 0.078 & 0.075 & 0.070 & 0.067 & 0.066 & 0.069 & 0.073 & 0.086 \\
\hline$\Delta_{\mathrm{H}-\mathrm{E}}$ & 0.095 & 0.088 & 0.083 & 0.085 & 0.095 & 0.101 & 0.103 & 0.100 \\
\hline$\Delta_{\mathrm{H}-\mathrm{I}}$ & 0.112 & 0.093 & 0.092 & NA & NA & NA & NA & NA \\
\hline \multicolumn{9}{|l|}{ April } \\
\hline$\sigma_{\mathrm{H}}$ & 0.041 & 0.045 & 0.045 & 0.043 & 0.042 & 0.042 & 0.046 & 0.054 \\
\hline$\Delta_{\mathrm{H}-\mathrm{E}}$ & 0.044 & 0.049 & 0.056 & 0.065 & 0.065 & 0.089 & 0.089 & 0.076 \\
\hline$\Delta_{\mathrm{H}-\mathrm{I}}$ & 0.047 & 0.045 & 0.047 & NA & NA & NA & NA & NA \\
\hline \multicolumn{9}{|l|}{ May } \\
\hline$\sigma_{\mathrm{H}}$ & 0.052 & 0.052 & 0.057 & 0.064 & 0.067 & 0.070 & 0.071 & 0.053 \\
\hline$\Delta_{\mathrm{H}-\mathrm{E}}$ & 0.057 & 0.060 & 0.063 & 0.078 & 0.103 & 0.123 & 0.130 & 0.125 \\
\hline$\Delta_{\mathrm{H}-\mathrm{I}}$ & 0.057 & 0.056 & 0.061 & NA & NA & NA & NA & NA \\
\hline \multicolumn{9}{|l|}{ June } \\
\hline$\sigma_{\mathrm{H}}$ & 0.031 & 0.031 & 0.033 & 0.038 & 0.042 & 0.046 & 0.049 & 0.041 \\
\hline$\Delta_{\mathrm{H}-\mathrm{E}}$ & 0.051 & 0.059 & 0.066 & 0.080 & 0.104 & 0.115 & 0.114 & 0.093 \\
\hline$\Delta_{\mathrm{H}-\mathrm{I}}$ & 0.049 & 0.044 & 0.050 & NA & NA & NA & NA & NA \\
\hline
\end{tabular}

and in the in situ and ECMWF datasets on the other. This could indeed be attributed to a difference in the characterization of the PBL top, as estimated from HAMSTRAD profiles and as calculated from ECMWF analyses, which may alter the diurnal cycle both in amplitude and phase. But, since ECMWF and in situ data agree relatively well, we could again point out a vertical resolution issue in the HAMSTRAD measurements (not better than $10 \mathrm{~m}$ ) that will tend to smear out the vertical profiles, thus affecting the actual location of the PBL top. The standard deviation of the HAMSTRAD temperature data (of about 3-6K) is far greater than the diurnal amplitude whilst the $\Delta_{\mathrm{H}-\mathrm{E}}$ bias ranges from -1 to $3 \mathrm{~K}$ below $200 \mathrm{~m}$, and the $\Delta_{\mathrm{H}-\mathrm{I}}$ bias is very high, from $\approx 3 \mathrm{~K}$ at $10 \mathrm{~m}$ decreasing to $1 \mathrm{~K}$ at $50 \mathrm{~m}$. For $\mathrm{H}_{2} \mathrm{O}$, the measured and analysed diurnal cycles are highly satisfactory, from a maximum after noon in the lowest layers to a maximum after midnight at $200 \mathrm{~m}$. The standard deviation $\sigma_{\mathrm{H}}$ of $\mathrm{H}_{2} \mathrm{O}$ is about $0.07-0.08 \mathrm{~g} \mathrm{~m}^{-3}$ below $200 \mathrm{~m}$, thus far greater than the diurnal cycle amplitudes $\left(0.015 \mathrm{~g} \mathrm{~m}^{-3}\right)$, with extremely high biases $\Delta_{\mathrm{H}-\mathrm{E}}$ and $\Delta_{\mathrm{H}-\mathrm{I}}\left(\approx 0.1 \mathrm{~g} \mathrm{~m}^{-3}\right)$. As in summer, the correlation between observed temperature and $\mathrm{H}_{2} \mathrm{O}$ is very high at $10 \mathrm{~m}(\approx 0.9)$ but very poor above $100 \mathrm{~m}(0.3-0.4)$. 
Table 3 Temperature-absolute humidity correlation using the HAMSTRAD $\left(r_{\mathrm{H}}\right)$ and the in situ $\left(r_{\mathrm{I}}\right)$ monthlymean hourly values from January to June 2010, at the heights of 10, 30, 50, 75, 100, 125, 150 and $200 \mathrm{~m}$

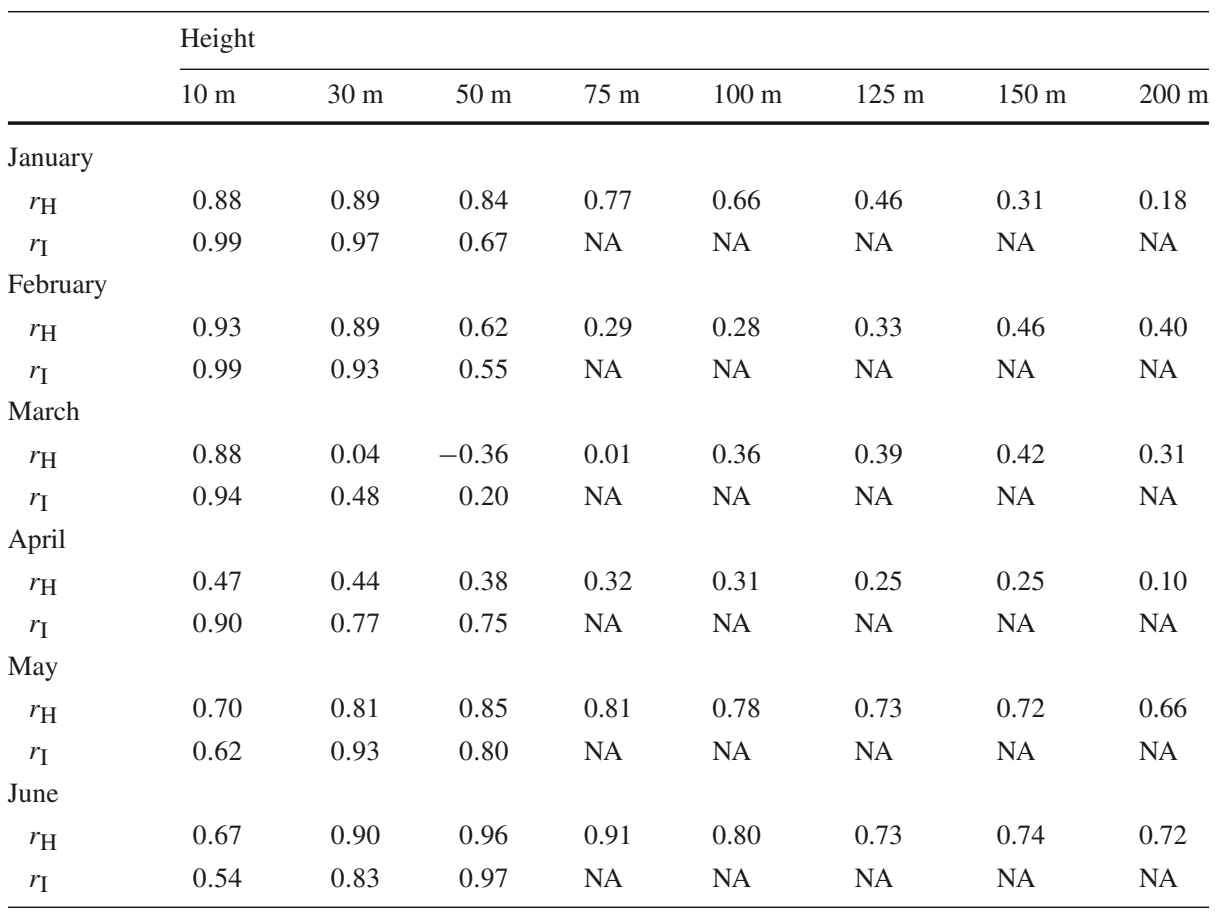

In winter (June, Fig. 10), a temperature diurnal cycle at $10 \mathrm{~m}$ is neither observed by HAMSTRAD nor on ECMWF analyses although a wide minimum of about $\pm 0.5 \mathrm{~K}$ amplitude, centred around noon, is observed in the in-situ data. At 30 and $50 \mathrm{~m}$ heights, a diurnal cycle is quite consistently measured by HAMSTRAD and in-situ sensors, but is not reproduced by the ECMWF analyses. Above $75 \mathrm{~m}$, there is a minimum around $0900 \mathrm{LST}$ in the HAMSTRAD data consistent with the ECMWF analyses for which the minimum is observed at 0800 LST because of the 6-h sampling. Below $200 \mathrm{~m}$, the standard deviation of $3-7 \mathrm{~K}$ is again much larger than the diurnal cycle amplitude $( \pm 0.5 \mathrm{~K}$ maximum), with high positive biases in $\Delta_{\mathrm{H}-\mathrm{E}}$ and $\Delta_{\mathrm{H}-\mathrm{I}}$ ranging from 7 to $1 \mathrm{~K}$ below $50 \mathrm{~m}$, reducing from 3 to $-1 \mathrm{~K}$ from 50 to $200 \mathrm{~m}$ when considering $\Delta_{\mathrm{H}-\mathrm{E}}$. At $10 \mathrm{~m}$ height, the diurnal $\mathrm{H}_{2} \mathrm{O}$ cycle as measured by HAMSTRAD shows a wide minimum centred around local noon of about $\pm 0.004 \mathrm{~g} \mathrm{~m}^{-3}$ amplitude. This is also observed in the in-situ dataset but above $30 \mathrm{~m}$. Above $100 \mathrm{~m}$, the diurnal cycle is rather weak $\left(<0.002 \mathrm{~g} \mathrm{~m}^{-3}\right)$ and much less than the standard deviation $\sigma_{\mathrm{H}}\left(0.04 \mathrm{~g} \mathrm{~m}^{-3}\right)$. The $\mathrm{H}_{2} \mathrm{O}$-temperature correlation, from HAMSTRAD and in-situ datasets, ranges from $\approx 0.6$ to 0.97 below $50 \mathrm{~m}$, and from 0.91 to 0.72 above $50 \mathrm{~m}$. The apparent diurnal cycle observed in winter cannot be attributed to any changes in the incoming shortwave radiation, since the shortwave flux is null at that time of the year, but rather to the methodology employed (monthly averaging) that mixes in a given 1 -h bin air masses from different origins, and thus produces an artificial diurnal cycle (sampling effect). 
In conclusion, the diurnal cycles in temperature and $\mathrm{H}_{2} \mathrm{O}$ as measured by HAMSTRAD and in situ sensors and from the ECMWF analyses show good agreement from summer to winter, with a temperature- $\mathrm{H}_{2} \mathrm{O}$ correlation very high $(0.6-0.9)$ below $50 \mathrm{~m}$, despite the fact that the amplitude of the cycles decreases with height and with the season (from summer to winter). Nevertheless, some differences are worthwhile mentioning, (1) in summer at $10 \mathrm{~m}$, the diurnal amplitude of $\mathrm{H}_{2} \mathrm{O}$ is four times greater in the ECMWF analyses and in the in-situ measurements than in HAMSTRAD data; (2) the analyzed and observed temperature diurnal cycles are out-of-phase by $12 \mathrm{~h}$ between 30 and $100 \mathrm{~m}$ heights in March, and between 30 and $50 \mathrm{~m}$ heights in June; and (3) a moist bias is observed in the HAMSTRAD data compared to ECMWF and in-situ data.

\section{Discussions}

Following the above analysis, we intend now to discuss the evolution of the PBL in time and height over Dome $\mathrm{C}$ depending on the considered season. To help, we show in Fig. 11 the diurnal variations of the potential temperature, calculated using a reference pressure of $650 \mathrm{hPa}$ (mean surface pressure at Dome C), based upon the HAMSTRAD, radiosonde, and in situ monthly-averaged measurements, together with the ECMWF monthly-averaged analyses at different seasons: summer (January 2010), autumn (March 2010) and winter (June 2010). Figure 12 shows a sketch of the 24-h temporal evolution of the different layers in the PBL according to the three considered seasons: summer, autumn/spring, winter. Note that the diurnal variations of temperature and $\mathrm{H}_{2} \mathrm{O}$ as measured by HAMSTRAD in October 2010 (spring) are very consistent with their variations in March 2010 (autumn) (not shown).

In order to highlight the temporal evolution versus height of the PBL, we use the concept presented by Stull (1988, Fig. 1.7) describing the different layers below the free troposphere. First of all, whatever the considered season, we expect that there is a thin layer at the interface of the snow surface and the atmosphere: the surface layer, with a top height $h_{0}$ being of the order of $10 \mathrm{~m}$. Secondly, we name $h_{2}$ the height between the free troposphere and the layer underneath. The actual value of $h_{2}$ will evolve along the season. Lastly, we name $h_{1}$, the top of any layer between the surface layer and the free troposphere, namely the top of the PBL. If $h_{1}$ exists, it will also evolve according to the season. We thus have: $h_{2}>h_{1}>h_{0}$.

In summertime, sunlight is present all day long at Dome C. As we already noticed in Sect. 2 due to the data averaging method, the top of the PBL $\left(h_{2}\right)$ cannot be fully characterized, but it ranges between 100 and $400 \mathrm{~m}$. Starting around midnight, the potential temperature has a positive gradient up to about $h_{1}$ (of the order of $50 \mathrm{~m}$ ), then evolves slightly up to $h_{2}$. This means that, above the surface layer, there is a stable boundary layer, followed by a residual quasi-mixed layer (we will see after where this layer comes from). Around local noon, the potential temperature does not show any vertical gradient, and a mixed layer develops from $h_{0}$ entirely up to $h_{2}$. After 1800 LST, a stable layer (positive gradient) develops from $h_{0}$ to $h_{1}$ because the surface temperature decreases but a residual of the mixed layer remains above. This represents a quite conventional PBL scheme in agreement with e.g. Stull (1988). Even though the incoming shortwave radiation remains positive all day long, it decreases from 1800 to 0600 LST at levels low enough to allow a stable boundary layer to develop, in a similar way to the mid-latitude nocturnal boundary layer. The transition between a stable boundary layer and a mixed layer starts around 0600 LST when the solar irradiation becomes significant, and gradually $h_{1}$ reaches $h_{2}$ around local noon. Around 1800 LST, the stable layer develops above the surface layer. 

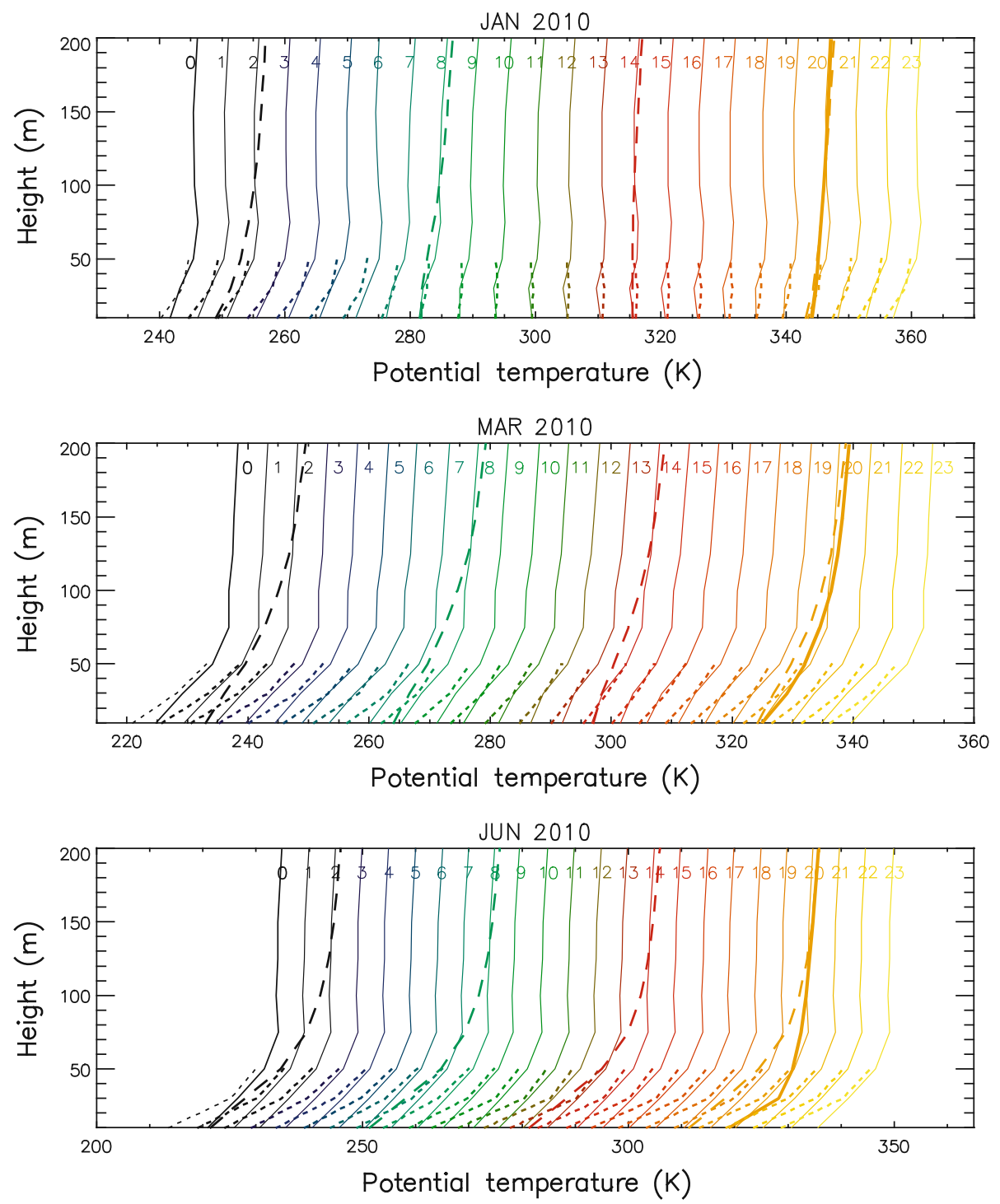

Fig. 11 From top to bottom: diurnal variations of the monthly-averaged potential temperatures in January, March and June 2010 from HAMSTRAD (solid line), radiosonde (thick solid line), and in situ (dotted line) measurements, together with the ECMWF (dashed line) analyses. Potential temperatures are calculated with a reference pressure of $650 \mathrm{hPa}$, the mean surface pressure at Dome C. Colours from dark blue to light yellow span the $0-24 \mathrm{~h}$ range by step of $1 \mathrm{~h}$. For better readability, all the vertical profiles for a given month are shifted by $5 \mathrm{~K}$ with respect to the preceding one

In autumn, the alternation between day and night occurs at Dome $\mathrm{C}$. The majority of time a strong positive gradient is present above the surface layer, producing a nocturnal stable boundary layer up to an altitude of $h_{2}$ (of the order of $50 \mathrm{~m}$ ), except around local noon. Indeed, around local noon, the radiative energy available at the surface allows the development of a daytime mixed layer from $h_{0}$ to $h_{1}$ (of the order $30 \mathrm{~m}$ ). Between $h_{1}$ and $h_{2}$, a 


\section{SUMMER}

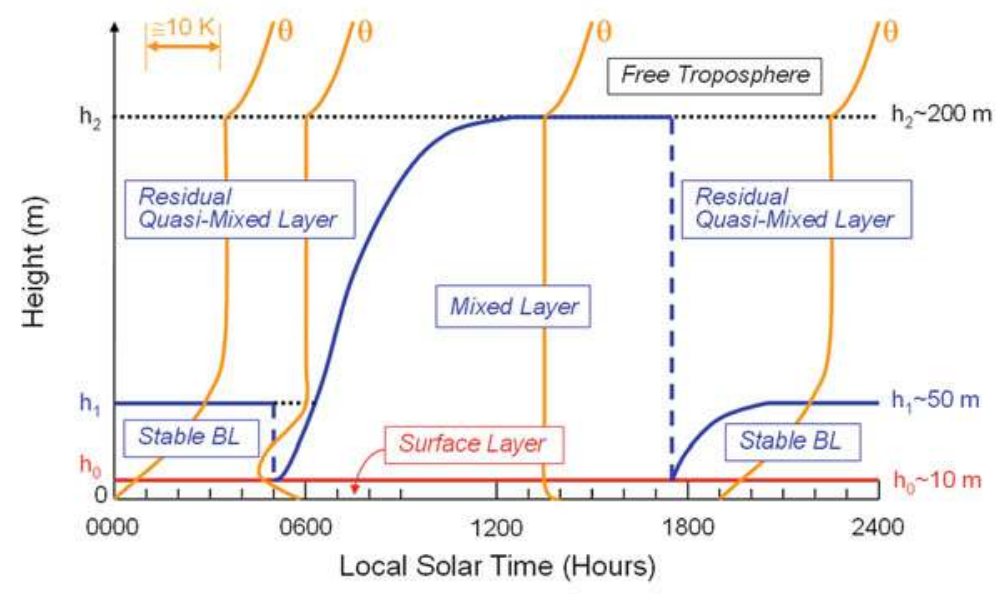

\section{AUTUMN/SPRING}

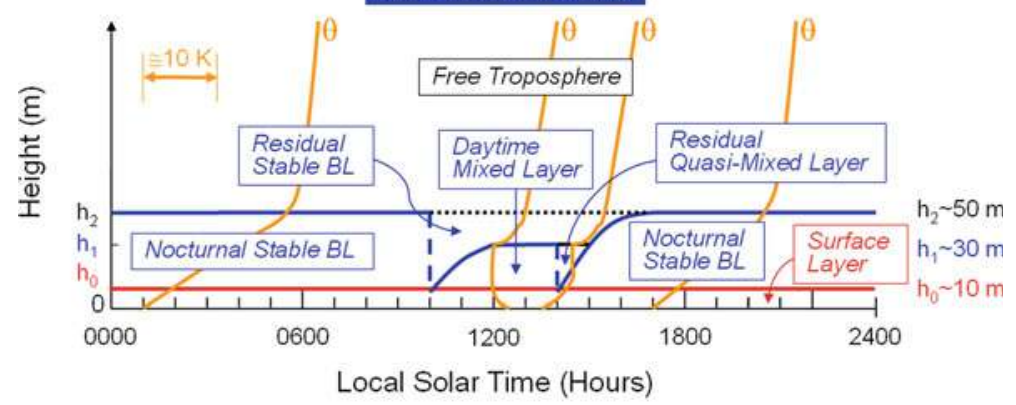

\section{WINTER}

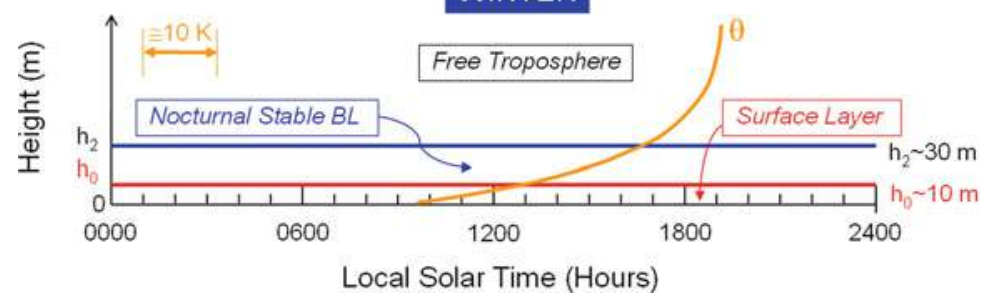

Fig. 12 24-h temporal evolution of the different layers in the PBL according to the seasons: summer (top), autumn/spring (middle), winter (bottom). The height $h_{0}$ represents the top of the surface layer, $h_{2}$ is the top of the PBL, and $h_{1}$ (whenever present) is the top height of the intermediate layer within the PBL. The orange lines symbolize the vertical profiles of potential temperature

residual stable boundary layer tends to persist. It is interesting to note that the top height of the mixed layer is lower than the top height of the nocturnal stable boundary layer. After the cessation of solar radiation, the nocturnal stable boundary layer starts developing from the surface. There is a possibility for a residual quasi-mixed layer to exist for some time above, until it is absorbed into the growing stable nocturnal boundary layer. 
In wintertime, when solar radiation is zero, the surface temperature is extremely low $\left(\approx-70^{\circ} \mathrm{C}\right)$ on average with extremes occasionally below $-80^{\circ} \mathrm{C}$ (Carminati et al. 2011a, manuscript in preparation), the potential temperatures do not change according to the local time. A strong positive gradient remains producing a nocturnal stable boundary layer above the surface layer up to the free troposphere, at $h_{2} \approx 30 \mathrm{~m}$.

\section{Conclusions}

The ground-based microwave radiometer HAMSTRAD was permanently deployed at the Dome C station (Antarctica) in January 2010 and has successfully operated since that date. It measures the vertical profiles of water vapour and temperature with a 7-min resolution. Since the measurement sensitivity is very high in the lowermost troposphere, we have concentrated our analysis on the diurnal variabilities of the monthly-averaged absolute humidity and temperature as observed by HAMSTRAD in the planetary boundary layer (from 10 to $200 \mathrm{~m}$ ) from summer (January 2010) to winter (June 2010). We have assessed the quality of the variabilities and of the vertical profiles by comparing with the monthly-averaged radiosondes launched at the station at 2000 LST, with the monthly-averaged outputs from the ECMWF analyses at 0200, 0800, 1400 and 2000 LST, and with the monthly-averaged in situ sensor measurements scanning the whole 24 -h period. The HAMSTRAD systematic error coming from different sources (calibration, spectroscopy, measurement technique at different elevations, retrieval method, etc.) estimated by considering the biases between HAMSTRAD and all the other datasets is found to be much greater than the random error, which can be minimized by averaging the data over a long time period, down to $0.01-0.04 \mathrm{~K}$ for temperature and $0.0007-0.002 \mathrm{~g} \mathrm{~m}^{-3}$ for $\mathrm{H}_{2} \mathrm{O}$ in hourly profiles for each month.

A strong diurnal cycle in temperature and $\mathrm{H}_{2} \mathrm{O}$ (although noisier) has been observed in summertime at $10 \mathrm{~m}$, decreasing in amplitude with height, and phase-shifted by about $4 \mathrm{~h}$ above $50 \mathrm{~m}$ with a strong $\mathrm{H}_{2} \mathrm{O}$-temperature correlation $(>0.8)$ in the entire PBL. In autumn, whilst the diurnal cycle in temperature and $\mathrm{H}_{2} \mathrm{O}$ has a smaller amplitude, a 12$\mathrm{h}$ phase shift is observed above $30 \mathrm{~m}$. In wintertime, the amplitude of the diurnal cycle is very small below $200 \mathrm{~m}$. Radiosondes at 2000 LST and ECMWF analyses at 0200, 0800, 1400 and 2000 LST agree very well with the HAMSTRAD diurnal cycles for temperature and relatively well for absolute humidity. For temperature, HAMSTRAD tends to show a smoother vertical profile compared to radiosonde data and in situ profiles, particularly obvious when moving from summer to winter. For $\mathrm{H}_{2} \mathrm{O}$, HAMSTRAD measures much more moist and unrealistic profiles compared to all the other datasets. The diurnal cycle at $10 \mathrm{~m}$ is much smaller in amplitude than that from radiosondes and the ECMWF models (by a factor of 4 in January 2010). A temperature- $\mathrm{H}_{2} \mathrm{O}$ correlation $>0.8$ is generally observed in the HAMSTRAD and the in situ datasets. In winter, the apparent diurnal cycle observed cannot be attributable to any changes in the incoming shortwave radiation since it is null at that time of year but rather to the methodology employed (monthly averaging), which mixes, in a given 1-h bin, air masses from different origins and thus produces an artificial diurnal cycle (sampling effect).

The vertical profiles of HAMSTRAD are smoother than those from in situ and radiosonde data, whatever the season considered, which is attributable to the poorer vertical resolution of HAMSTRAD, evaluated to be $10-20 \mathrm{~m}$ for temperature and $25-50 \mathrm{~m}$ for $\mathrm{H}_{2} \mathrm{O}$, below $200 \mathrm{~m}$.

All the datasets used in our analysis have helped characterize the temporal evolution of the PBL according to the season, from an elevated summertime mixed PBL at 
about $200 \mathrm{~m}$, to a wintertime stable PBL at about $30 \mathrm{~m}$. Furthermore we have highlighted different layers within the PBL that develop differently: from a long-lasting residual quasi-mixed layer following a mixed layer centred at local noon in summer to a long-lasting nocturnal stable boundary layer bracketing a short daytime mixed layer centred at local noon in autumn. In winter, only a nocturnal stable boundary layer is present.

In the future, measurements from sonic anemometers deployed in 2010 on the $45-\mathrm{m}$ high tower will complement our analysis. These devices will help characterize the seasonal variation of the PBL height. In parallel, the HAMSTRAD retrievals of temperature and $\mathrm{H}_{2} \mathrm{O}$ will be updated and should produce less noisy and more realistic $\mathrm{H}_{2} \mathrm{O}$ profiles in the lowermost troposphere. Finally, the HAMSTRAD radiometer remains a unique autonomous instrument in the way in which it scans throughout the troposphere with a high sampling rate, and yielding mostly reliable results.

Acknowledgments The HAMSTRAD programme has been funded by the Institut National des Sciences de l'Univers (INSU)/Centre National de la Recherche Scientifique (CNRS), the Institut polaire français PaulEmile Victor (IPEV) and the Centre National d'Etudes Spatiales (CNES). We would like to thank all the French and Italian staff (technicians, engineers and scientists) who has worked at the Concordia Base over the January-June 2010 period. Finally, we would like to thank Stephen Hudson and one anonymous reviewer for their very fruitful comments.

\section{Appendix}

Although the expected vertical resolution of the HAMSTRAD temperature and $\mathrm{H}_{2} \mathrm{O}$ measurements is 50 and $100 \mathrm{~m}$, respectively (Ricaud et al. 2010a), we have used the opportunity of our study related to the PBL height to refine these estimates. Indeed, we have estimated the height of the PBL with respect to the month to be $\approx 200 \mathrm{~m}$ in January, $\approx 50 \mathrm{~m}$ in March and $\approx 30 \mathrm{~m}$ in June. We have considered on Fig. 13 the temperature-temperature correlation versus height of the HAMSTRAD data over the period January-June 2010. This represents the correlation between monthly-averaged diurnal temperature time series at two different heights. If we suppose a well-mixed atmosphere or an atmosphere uniformly varying with respect to time along the vertical, the off-diagonal terms of the correlation matrix will be close to unity whatever the height and whatever the vertical resolution. If we now suppose an atmosphere that does not vary uniformly along the vertical (e.g., with an obvious transition between the PBL and the free atmosphere at an altitude $h_{2}$ ), the off-diagonal terms will thus depart from unity and will reach a value of 0.8 at an altitude $h_{2}{ }^{\prime}$ (we arbitrarily consider that two terms are no longer correlated when their correlation coefficient is below the value of 0.8 ). Note that using a threshold value ranging from 0.7 to 0.9 does not significantly change our conclusions. The vertical resolution of the measurements $\Delta_{1 / 2}$ can be estimated by the quantity $\Delta_{1 / 2}=\left|h_{2}-h_{2}^{\prime}\right|$. The best period to characterize $\Delta_{1 / 2}$ is of course March 2010 since the transition $h_{2}$ is obviously detected and rather close to the surface. For $h_{2}=50 \mathrm{~m}$, we can find $h_{2}{ }^{\prime}=40 \mathrm{~m}$. For instance, in February 2010, for $h_{2}=50 \mathrm{~m}$, we find $h_{2}{ }^{\prime}=70 \mathrm{~m}$. Thus the vertical resolution $\Delta_{1 / 2}$ of the HAMSTRAD temperature measurements below $200 \mathrm{~m}$ can be estimated to be $\Delta_{1 / 2}=10-20 \mathrm{~m}$.

We intend now to estimate the vertical resolution $\Delta_{1 / 2}$ of the $\mathrm{H}_{2} \mathrm{O}$ HAMSTRAD measurements by considering the $\mathrm{H}_{2} \mathrm{O}-\mathrm{H}_{2} \mathrm{O}$ correlation matrix versus height (see Fig. 14) according to the months from January to June 2010. Again, the best period is in March since the transition between the PBL and the free troposphere is obvious at $h_{2}=50 \mathrm{~m}$ and we find $h_{2}{ }^{\prime}=75 \mathrm{~m}$. For instance, in February, as for temperature, for $h_{2}=50 \mathrm{~m}$, we find $h_{2}^{\prime}=100 \mathrm{~m}$. Thus 


\section{HAMSTRAD Temperature Correlation}
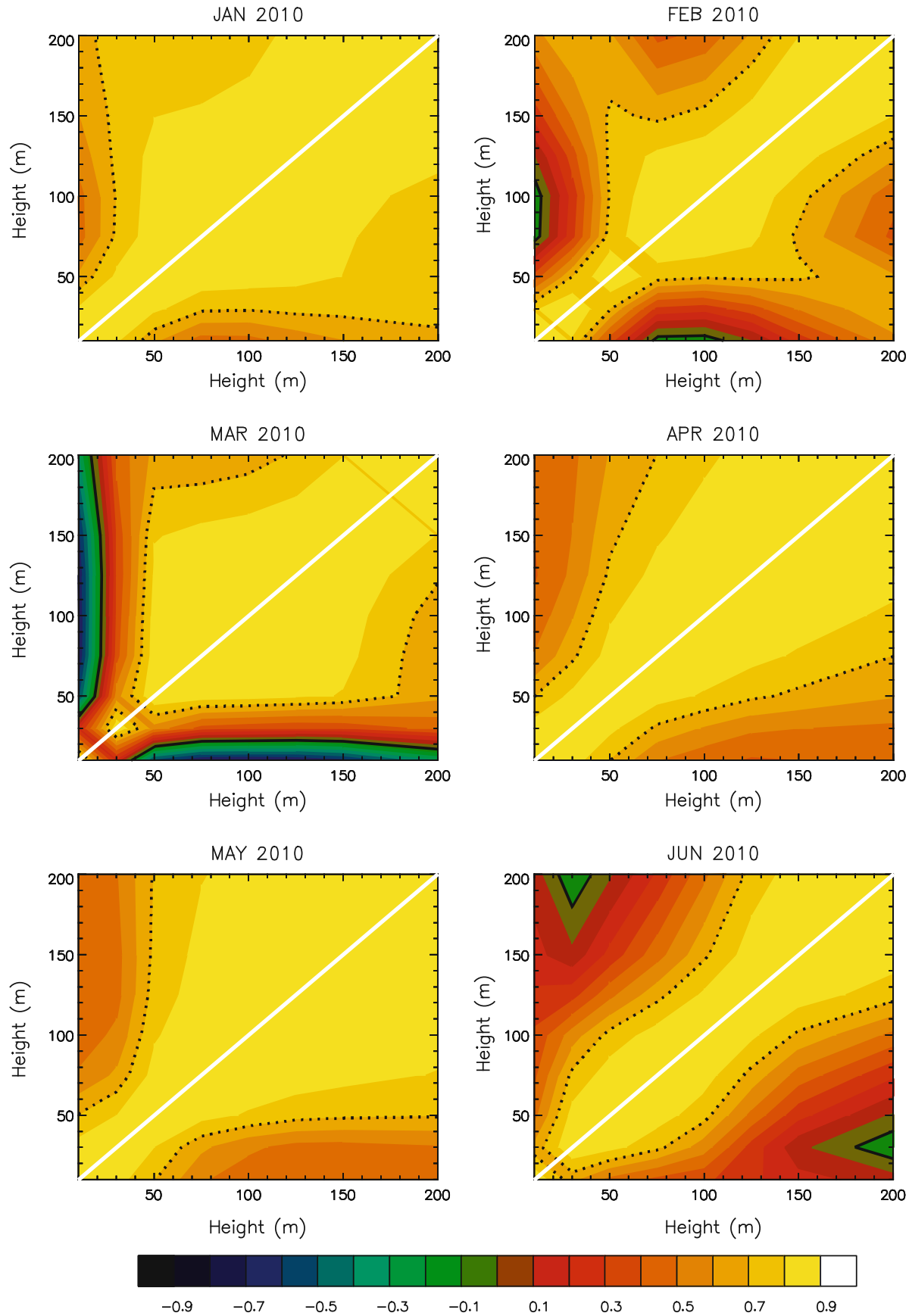

Fig. 13 Correlation between monthly-averaged diurnal temperature time series at two different heights (represented on the two axes of the diagrams) from HAMSTRAD data in January-June 2010. The black solid line represents a correlation of 0 , and the black dotted line a correlation of 0.80 

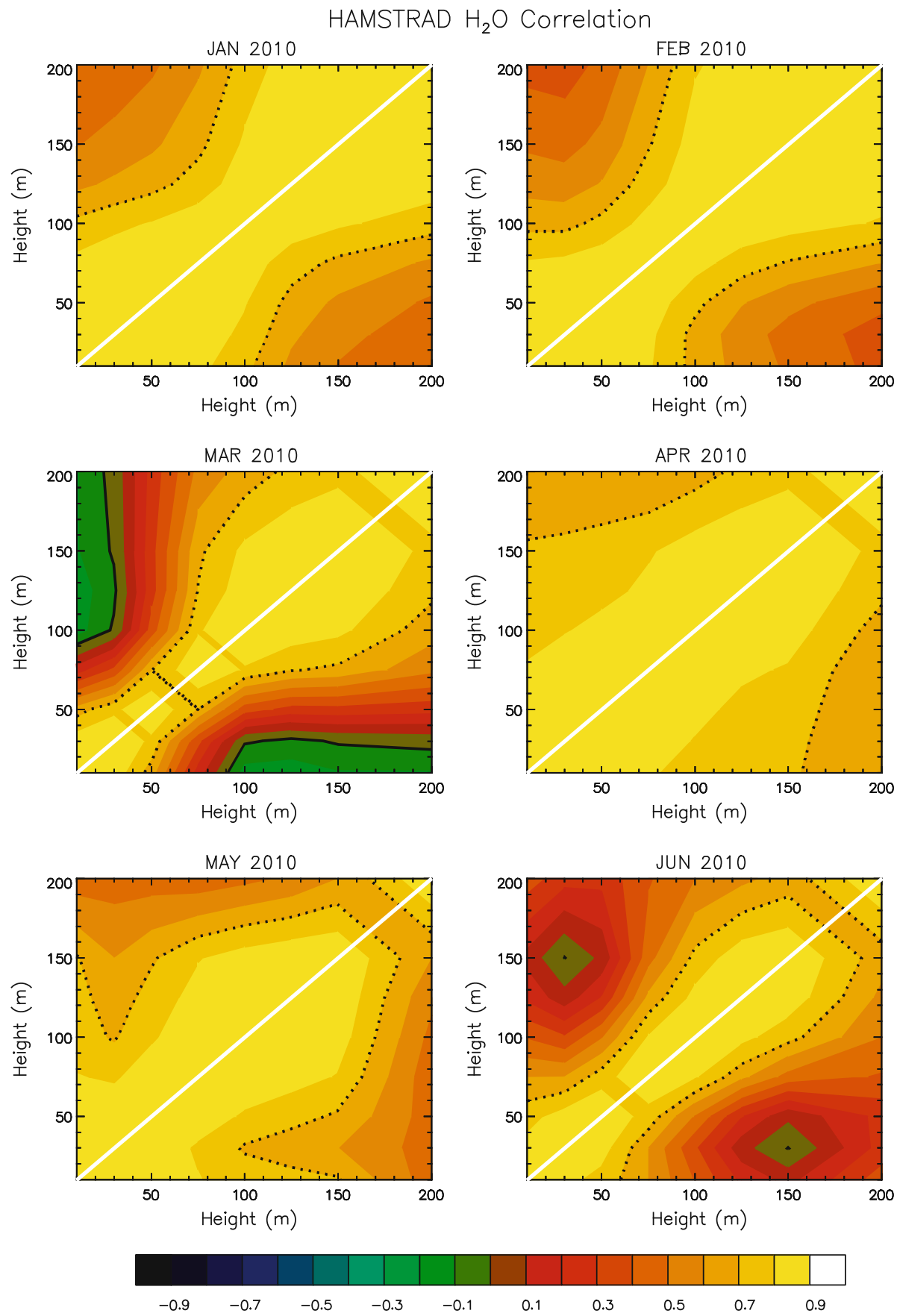

Fig. 14 Same as Fig. 13 but for the absolute humidity 
the vertical resolution $\Delta_{1 / 2}$ of the HAMSTRAD $\mathrm{H}_{2} \mathrm{O}$ measurements below $200 \mathrm{~m}$ can be estimated to be $\Delta_{1 / 2}=25-50 \mathrm{~m}$.

\section{References}

Argentini S, Viola A, Sempreviva AM, Petenko I (2005) Summer boundary-layer height at the plateau site of Dome C, Antarctica. Boundary-Layer Meteorol 115:409-422

Aristidi E, Agabi K, Vernin J, Azouit M, Martin F, Ziad A, Fossat E (2003) Antarctic site testing: first daytime seeing monitoring at Dome C. Astron Astrophys 406:19-22

Aristidi E, Agabi K, Azouit M, Fossat E, Vernin J, Travouillon T, Lawrence JS, Meyer C, Storey JWV, Halter B, Roth WL, Walden V (2005) An analysis of temperatures and wind speeds above Dome C, Antarctica. Astron Astrophys 430:739-746

Cimini D, Westwater ER, Gasiewski AJ, Klein M, Leuski VY, Liljegren JC (2007a) Ground-based millimeterand submillimeter-wave observations of low vapor and liquid contents. IEEE Trans Geosci Remote Sens 45:2169-2180

Cimini D, Westwater ER, Gasiewski AJ, Klein M, Leuski VY, Dowlatshabi S (2007b) The ground-based scanning radiometer: a powerful tool for study of the Arctic atmosphere. IEEE Trans Geosci Remote Sens 45:2759-2777

Connolley WM (1996) The Antarctic temperature inversion. Int J Climatol 16:1333-1342

Davis D, Nowak JB, Chen G, Buhr M, Arimoto R, Hogan A, Eisele F, Mauldin L, Tanner D, Shetter R, Lefer B, McMurry P (2001) Unexpected high levels of NO observed at South Pole. Geophys Res Lett 28:3625-3628

Genthon C, Town MS, Six D, Favier V, Argentini S, Pellegrini A (2010) Meteorological atmospheric boundary layer measurements and ECMWF analyses during summer at Dome C, Antarctica. J Geophys Res. doi:10.1029/2009JD012741

Hines KM, Bromwich DH, Rasch PJ, Iacono MJ (2004) Antarctic clouds and radiation within the NCAR climate models. J Clim 17:1198-1212

Hudson SR, Brandt RE (2005) A look at the surface-based temperature inversion on the Antarctic Plateau. J Clim 18:1673-1696

Jones AE, Weller R, Andreson PS, Jacobi HW, Wolff EW, Schrems O, Miller H (2001) Measurements of NOx emissions from the Antarctic snowpack. Geophys Res Lett 28:1499-1502

King JC, Argentini S, Anderson P (2006) Contrasts between the summertime surface energy balance and boundary layer structure at Dome C and Halley stations, Antarctica. J Geophys Res. doi:10.1029/ 2005JD006130

Mattioli V, Westwater ER, Cimini D, Gasiewski AJ, Klein M, Leuski VY (2008) Microwave and Millimeter-wave Radiometric and Radiosonde observations in an Arctic environment. J Atmos Ocean Technol $25: 1768-1777$

Pazmany AL (2007) A compact 183-GHz radiometer for water vapor and liquid water sensing. IEEE Trans Geosci Remote Sens 45:2202-2206

Racette PE, Westwater ER, Han Y, Gasiewski A, Klein M, Cimini D, Manning W, Kim E, Wang J, Kiedron $P$ (2005) Measurement of low amounts of precipitable water vapor using ground-based millimeterwave radiometry. J Atmos Ocean Technol 22:317-337

Ricaud P, Gabard B, Derrien S, Chaboureau J-P, Rose T, Mombauer A, Czekala H (2010a) HAMSTRADTropo, A 183-GHz Radiometer dedicated to sound tropospheric water vapor over Concordia Station, Antarctica. IEEE Trans Geosci Remote Sens 48:1365-1380

Ricaud P, Gabard B, Derrien S, Attié J-L, Rose T, Czekala H (2010b) Validation of tropospheric water vapor as measured by the 183-GHz Radiometer HAMSTRAD-Tropo over the Pyrenees Mountains, France. IEEE Trans Geosci Remote Sens 48:2189-2203

Ricaud P, Derrien S, Chaboureau J-P, Attié J-L, Rose T, Czekala H, Genthon C, Genoni L, Pellegrini A, Durand G (2010c) The 183-GHz Radiometer HAMSTRAD: first measurements of temperature and humidity in the PBL at Dome C (Antarctica). In: ISARS 2010 Symposium, Paris, France

Ricaud P, Carminati F, Attié J-L, Canut G, Derrien S, Courcoux Y, Rose T, Genthon C, Six D, Genoni L, Pellegrini A, Durand G, Tremblin P, August T, Vanacker J-F (2011) Quality assessment of the first measurements of tropospheric water vapor and temperature by the HAMSTRAD Radiometer over Concordia Station, Antarctica. IEEE Trans Geosci Remote Sens, in press

Stratospheric Processes And their Role in Climate (2000) In: Kley D, Russell JM III, Phillips C (eds) SPARC Assessment of Upper Tropospheric and Stratospheric Water Vapour, $312 \mathrm{pp}$

Stull RB (1988) An introduction to boundary layer meteorology. Kluwer, Dordrecht, 666 pp 
Tomasi C, Petkov B, Benedetti E, Vitale V, Pellegrini A, Dargaud G, De Silvestri L, Grigioni P, Fossat E, Roth WL, Valenziano L (2006) Characterization of the atmospheric temperature and moisture conditions above Dome C (Antarctica) during austral summer and fall months. J Geophys Res. doi:10.1029/ 2005JD006976

Town MS, Walden VP (2009) The surface energy budget and behavior of the stable boundary layer over the South Pole. J Geophys Res. doi:10.1029/2009JD011888

Tremblin P, Minier V, Schneider N, Durand G, Challita Z, Fossat E, Reinert Y, Ricaud P, Sabbatini L, Storey J, Urban J, Veyssiere C, Walter C (2011) Site testing for submillimetre astronomy at Dome C in Antarctica. Astron Astrophys, in press

Westwater ER, Crewell S, Mätzler C (2004) A review of surface-based microwave and millimeter-wave radiometric remote sensing of the troposphere. Radio Sci Bull 3010:59-80

Westwater ER, Cimini D, Mattioli V, Gasiewski A, Klein M, Leuski V, Liljegren J (2006) The 2004 North Slope of Alaska Arctic Winter Radiometric Experiment: overview and highlights. In: Proc Microw Spec Meeting, San Juan, Puerto Rico, pp 77-81 